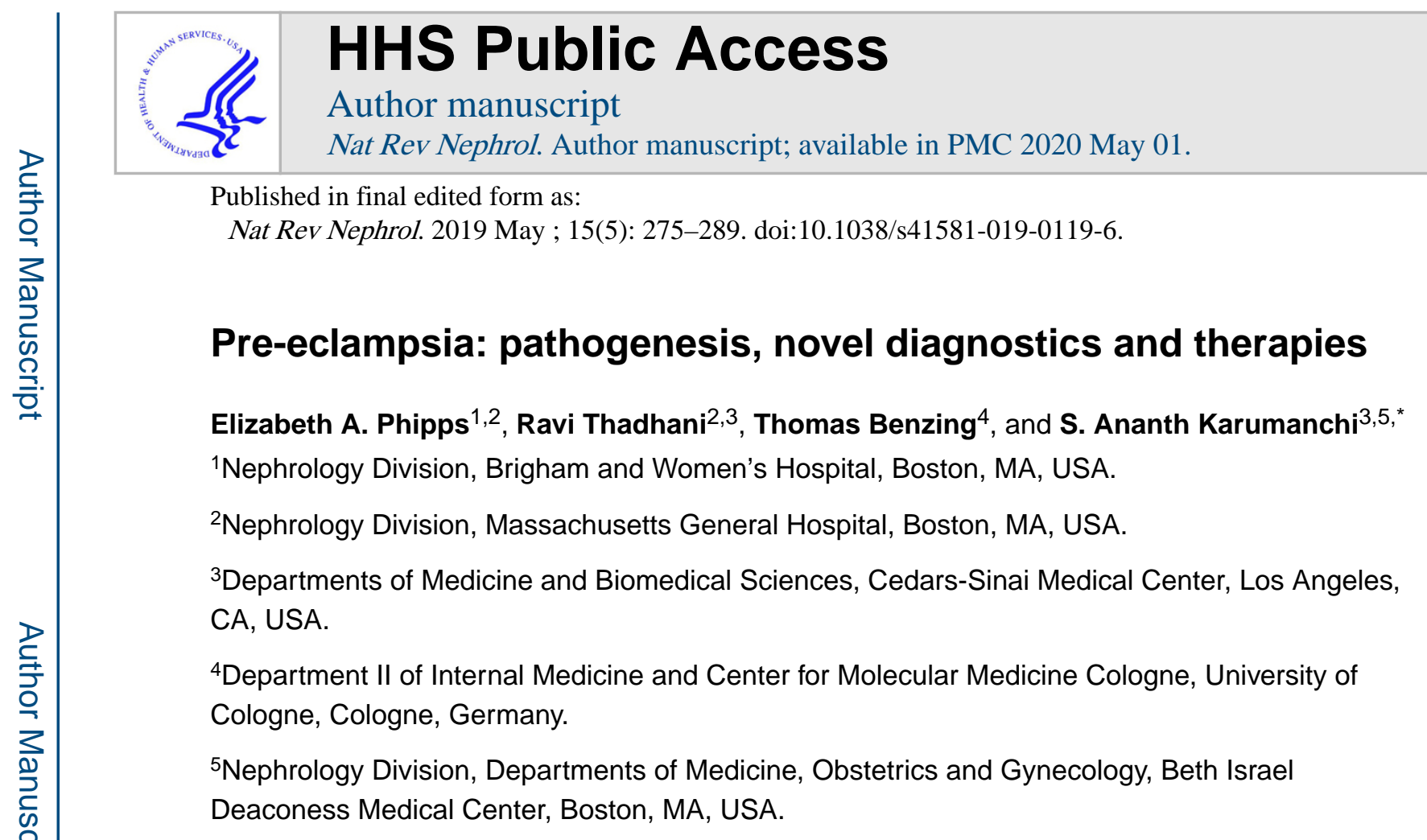

\title{
Abstract
}

Pre-eclampsia is a complication of pregnancy that is associated with substantial maternal and fetal morbidity and mortality. The disease presents with new-onset hypertension and often proteinuria in the mother, which can progress to multi-organ dysfunction, including hepatic, renal and cerebral disease, if the fetus and placenta are not delivered. Maternal endothelial dysfunction due to circulating factors of fetal origin from the placenta is a hallmark of pre-eclampsia. Risk factors for the disease include maternal comorbidities, such as chronic kidney disease, hypertension and obesity; a family history of pre-eclampsia, nulliparity or multiple pregnancies; and previous preeclampsia or intrauterine fetal growth restriction. In the past decade, the discovery and characterization of novel antiangiogenic pathways have been particularly impactful both in increasing understanding of the disease pathophysiology and in directing predictive and therapeutic efforts. In this Review, we discuss the pathogenic role of antiangiogenic proteins released by the placenta in the development of pre-eclampsia and review novel therapeutic strategies directed at restoring the angiogenic imbalance observed during pre-eclampsia. We also highlight other notable advances in the field, including the identification of long-term maternal and fetal risks conferred by pre-eclampsia.

\footnotetext{
*SAnanth.Karumanchi@csmc.edu.

Author contributions

E.A.P and S.A.K. researched the data for and wrote the article. All authors made substantial contributions to discussions of the content and reviewed or edited the text before submission.

Competing interests

S.A.K. is co-inventor on multiple patents (US Patent and Trademark Office (USPTO) \#7,740,849, \#7,407,658, \#7,335,362, \#7,344,892 and \#8969322B2) related to the use of angiogenic markers for the diagnosis, prediction and therapy of pre-eclampsia. R.T. is a coinventor on a patent (USPTO \#7,344,892) related to the use of angiogenic proteins for the prediction of pre-eclampsia. These patents are held at Harvard Hospitals (Beth Israel Deaconess Medical Center and Massachusetts General Hospital). S.A.K and R.T. have financial interests in Aggamin Therapeutics LLC and have previously served as consultants for Roche Diagnostics and ThermoFisher. S.A.K. has received a research grant from Siemens. R.T. and T.B. have received a research grant from Kaneka Pharmaceuticals. The other authors report no competing interests.

Publisher's note

Springer Nature remains neutral with regard to jurisdictional claims in published maps and institutional affiliations.
} 
Pre-eclampsia is a leading complication of pregnancy that affects an estimated 4-5\% of pregnancies worldwide ${ }^{1-4}$. This disease incurs a large burden of maternal and fetal morbidity and mortality, with substantial contributions to prematurity of the fetus and longterm cardiovascular disease (CVD) in the mother ${ }^{5}$. Pre-eclampsia is defined as the presence of new-onset hypertension and proteinuria or other end-organ damage occurring after 20 weeks gestation ${ }^{6}$, whereas eclampsia is defined as the development of grand mal seizures in a woman with pre-eclampsia.

One of the earliest descriptions of pre-eclampsia was published in 1637 by Francois Mauriceau, an early pioneer of the specialty of obstetrics ${ }^{7}$. He noted the high risk of seizures in pre-eclampsia as well as the increased risk of this condition in primigravidas. Mauriceau attributed the development of eclamptic seizures to either abnormal lochial blood flow or intrauterine fetal death. In the 1700s, Boissier de Sauvages theorized that eclamptic seizures were nature's attempt to rid itself of a "morbid element". He made the important distinction between epilepsy and eclampsia on the basis of the resolution of symptoms postpartum in the latter. Preeclampsia was further defined in 1843 by John Lever, who found that the urine of women with pre-eclampsia contained albumin, and by Robert Johns, who noted the characteristic symptoms of headache, vision changes and oedema in affected patients ${ }^{7}$. In the 1960s, researchers discovered the involvement of impaired placental implantation in preeclampsia, and in 1989 Roberts et al. hypothesized that the impaired placental perfusion seen in pre-eclampsia led to widespread maternal endothelial dysfunction ${ }^{8}$.

The past two decades have seen major advances in the field of pre-eclampsia, although the underlying pathogenesis remains elusive ${ }^{9}$. Currently, the disease can be understood in terms of both placental and maternal dysfunction. Various genetic, angiogenic, structural and metabolic pathways have been implicated in pre-eclampsia, including spiral artery remodelling, placental oxygenation, redox and immune tolerance at the maternal-fetal interface and the balance of angiogenic and antiangiogenic factors. In particular, certain antiangiogenic proteins have emerged as key pathogenic mediators of the maternal disease, and their discovery has provided opportunities for the development of novel diagnostics such as risk calculators, prediction models and triage tools. These antiangiogenic proteins have also become attractive therapeutic targets, and several strategies are being developed for their inhibition, removal and blockade both in vitro and in vivo ${ }^{10,11}$.

Here, we review the epidemiology, diagnosis, pathogenesis, prevention and treatment of preeclampsia. We highlight the pathogenic role of antiangiogenic proteins that are released by the placenta and discuss novel therapeutic strategies that are directed at restoring the angiogenic imbalance that is observed during pre-eclampsia.

\section{Epidemiology and risk factors}

Pre-eclampsia and eclampsia are estimated to cause over 50,000 maternal deaths worldwide per year ${ }^{12}$, with substantial variance in frequency by geographical region. In industrialized countries, rates of hypertensive disorders of pregnancy have risen, with African-American women at higher risk of associated mortality than Hispanic, American-Indian, white and Asian or Pacific-Islander women ${ }^{13}$. By contrast, the rate of eclampsia has declined in the 
setting of more widespread antenatal care and use of magnesium sulfate ${ }^{14}$. In the USA, the incidence of hypertensive disorders in pregnancy (pre-eclampsia, eclampsia, gestational hypertension and chronic hypertension) is estimated to be $5.9 \%$, according to the National Hospital Discharge Survey, which monitored $\sim 39$ million births over a 10 -year period ${ }^{15}$. This study also showed that women with pre-eclampsia or eclampsia had a 3-25-fold increased risk of severe complications in their index pregnancy, including abruptio placentae, disseminated intravascular coagulation, pulmonary oedema and aspiration pneumonia.

Debate is ongoing regarding the heterogeneity of preeclampsia as the epidemiology, clinical presentation and associated morbidity differs between early-onset or 'placental' preeclampsia (occurring before 34 weeks) and late-onset or 'maternal' pre-eclampsia (occurring after 34 weeks) ${ }^{16,17}$. For example, early-onset pre-eclampsia is associated with substantial risk of intrauterine growth restriction, whereas late-onset disease is frequently associated with maternal obesity and large-for-gestational-age neonates ${ }^{18}$. Although the clinical presentations vary among the early-onset and late-onset subtypes of pre-eclampsia, transcriptional profile studies indicate a common gene signature in the maternal blood for both of these subtypes, suggesting that the mechanisms of maternal vascular injury are likely more similar than previously thought ${ }^{19}$.

Determinants of pre-eclampsia include family history, genetic predisposition, duration of sexual cohabitation, maternal smoking, number of pregnancies, maternal age, use of in vitro fertilization and maternal medical conditions such as pre-existing hypertension, diabetes, chronic kidney disease (CKD) and obesity ${ }^{20,21}$ (BOX 1). Conditions that are associated with increased placental mass, such as multifetal gestations and hydatidiform mole, are also associated with increased pre-eclampsia risk ${ }^{9}$, whereas trisomy 13 is associated with a high risk of preeclampsia ${ }^{22}$. People who were the products of pregnancies that were complicated by pre-eclampsia are at increased risk of having or fathering a pregnancy that is complicated by pre-eclampsia ${ }^{23,24}$, and this risk persists beyond their first pregnancies ${ }^{25}$. Pre-eclampsia heritability is estimated at $-55 \%$, with both maternal and fetal genetic contributions to risk (30-35\% and $20 \%$, respectively $)^{26}$. A large genome-wide association study reported compelling evidence that alterations near the fms-like tyrosine kinase 1 (FLTI) locus in the human fetal genome may be causal in the development of pre-eclampsia ${ }^{27}$.

\section{Diagnosis and classification}

The Task Force on Hypertension in Pregnancy of the American Congress of Obstetricians and Gynecologists (ACOG) introduced a classification for pre-eclampsia in 1972 and updated this classification in 2013 (REF. ${ }^{6}$ ). Currently, the ACOG Task Force classifies hypertension in pregnancy into one of four categories: pre-eclampsia-eclampsia, chronic hypertension, chronic hypertension with superimposed pre-eclampsia, and gestational hypertension.

Pre-eclampsia was initially defined as a rise in systolic blood pressure to $\geq 140 \mathrm{mmHg}$ or in diastolic pressure to $290 \mathrm{mmHg}$ on two separate occasions in a patient who was previously normotensive, as well as proteinuria of $\geq 300 \mathrm{mg}$ in a 24 -hour collection, of $0.3 \mathrm{~g} / \mathrm{g}$ by urine 
protein:creatinine ratio or +1 by urine dipstick if quantitative methods are unavailable, occurring after 20 weeks of pregnancy. The updated classification eliminated proteinuria as a requirement for diagnosis in the presence of other end-organ damage such as thrombocytopenia, impaired liver function, new renal insufficiency, pulmonary oedema or new-onset cerebral or visual disturbances. Pre-eclampsia with severe features is defined as pre-eclampsia with any of the following features: blood pressure $\geq 160 / 110 \mathrm{mmHg}$ on two separate occasions; platelet count $<100,000$ per microlitre; impaired liver function evidenced by abnormally elevated liver enzymes to twice the normal concentration or severe persistent right upper quadrant or epigastric pain; renal failure with a serum creatinine level of $>1.1$ $\mathrm{mg} / \mathrm{dl}(97.2 \mu \mathrm{mol} / \mathrm{l})$; or doubling of the serum creatinine level, pulmonary oedema or newonset cerebral or visual disturbances ${ }^{6}$.

\section{Management}

Currently, the only definitive treatment for pre-eclampsia is delivery of the fetus, although ongoing work on novel therapies seems promising. Management consists of preconception counselling, perinatal blood pressure control and management of complications, timely delivery of the fetus and postpartum surveillance. The ACOG recommends preconception counselling for any woman who has previously had pre-clampsia ${ }^{6}$. For women with preeclampsia without severe features at less than 37 weeks of pregnancy, expectant management is suggested; after 37 weeks, delivery rather than observation is suggested. For women with pre-eclampsia with severe features at or beyond 34 weeks or in those with unstable maternal or fetal conditions irrespective of gestational age, maternal stabilization and delivery are recommended. Women with pre-eclampsia with severe features at less than 34 weeks who are otherwise stable are recommended to receive corticosteroids to promote fetal lung maturity and to continue pregnancy at a facility with adequate maternal and neonatal intensive care. For women with eclampsia and pre-eclampsia with severe features, the ACOG strongly recommends administration of parenteral magnesium sulfate, with continuation intraoperatively and postpartum for women undergoing caesarean section ${ }^{6}$.

Recommendations for postpartum surveillance for women with gestational hypertension, pre-eclampsia or superimposed pre-eclampsia include blood pressure monitoring in the hospital or with equivalent outpatient surveillance for at least 72 hours and again at 7-10 days after delivery or earlier in women with symptoms of high blood pressure. It is recommended that all women postpartum, not just those with pre-eclampsia, receive discharge instructions including information about the signs and symptoms of preeclampsia. Studies of postpartum surveillance for new-onset hypertension indicate that postpartum hypertension and postpartum pre-eclampsia are more common than previously thought, and evidence suggests that affected women have angiogenic profiles that are similar to women with pre-eclampsia and therefore may represent a group with subclinical or unresolved pre-eclampsia ${ }^{28}$.

\section{Pathogenesis}

The pathogenesis of pre-eclampsia can be considered to involve two stages: abnormal placentation and the development of the maternal syndrome (FIG. 1). 


\section{Abnormal placentation}

Pre-eclampsia is understood to originate in the placenta, and its initial stages can be understood as the placental syndrome. The presence of the placenta, as opposed to the fetus, is essential to the development of pre-eclampsia, which is evident by the development of the condition in hydatidiform mole ${ }^{29}$. Common pathological findings in pre-eclamptic placentae include atherosis, sclerotic narrowing of arteries and arterioles, fibrin deposition and infarcts, which are all consistent with placental hypoperfusion and ischaemia and seem to correlate with the severity of pre-eclampsia ${ }^{30}$. In addition, marked hypertrophy of the media in the decidual vessels, known as hypertrophic decidual vasculopathy, has been reported ${ }^{30}$ (FIG. 2).

Pre-eclampsia is a human disease that does not seem to occur in other species. The reason for this specificity is thought to be the disparately high ratio of brain:body weight of the human fetus, which requires $60 \%$ of nutritional exchange from the mother in the third trimester in comparison with only $20 \%$ of nutritional exchange in other mammals ${ }^{16}$. Normal placentation is characterized by structural alterations and adaptations of the maternal vessels to accommodate the requisite blood flow to the developing fetus ${ }^{31}$. The radial arteries of the uterus divide into two or more branches, which either terminate in the myometrium or decidua (basal arteries) or open into the intervillous space (spiral arteries). Opening into the intervillous space is affected by the cytotrophoblasts, which invade the spiral arteries in early pregnancy and induce fibrinoid necrosis of the vessel walls. Towards term, these spiral arteries demonstrate an absence of muscular and elastic tissue, have no continuous endothelial lining and frequently contain mural thrombi. Transformation of the spiral arteries from small muscular arteries to large tortuous vessels is hypothesized to be required to accommodate the enormous blood flow requirements of the placenta and to override the vasomotor control of the maternal arteries ${ }^{31}$.

Placental ischaemia and hypoxia.-The characteristics of pre-eclamptic placenta have been studied for well over a century. In 1914, Young observed an increased frequency of placental infarcts in women with "toxaemia, albuminuria and eclampsia" compared with pregnant women without albuminuria ${ }^{32}$. The infarcts suggested placental hypoperfusion and ischaemia. In the 1960s, several groups attempted to elucidate the differences in placentation in pre-eclamptic and normotensive pregnancies. A study of $>100$ placental bed biopsy samples from women with various hypertensive disorders of pregnancy reported that samples from women with chronic hypertension demonstrated hyperplasia and arteriosclerosis with proliferation of the intima and media of the basal and spiral arteries as well as frequent mural thrombi of the spiral arteries ${ }^{33}$. These features were markedly distinct from those seen in samples of pre-eclamptic and eclamptic placental beds in which the vessels showed acute fibrinoid necrosis of the vessel wall and the presence of foam cells, indicating acute atherosis. Lipophage infiltration and complete thrombotic occlusion of vessels were also frequently seen in the pre-eclamptic placental beds.

Further support for the ischaemic placenta hypothesis was provided by the demonstration that in preeclampsia, the physiological changes of the spiral arteries were restricted to the decidua, whereas in normal pregnancy they extended proximally into the myometrium ${ }^{34}$. 
Furthermore, in their series of placental bed biopsy samples, the average diameter of the spiral arteries in pre-eclamptic samples was only $200 \mu \mathrm{m}$, as opposed to $500 \mu \mathrm{m}$ in the vessels of placentae from normal pregnancies. This superficial invasion of the decidua results in narrow and undilated proximal segments of the spiral arteries, which ultimately leads to uterine hypoperfusion and higher-than-normal velocity of blood flow to the intervillous space ${ }^{35-38}$. These findings were confirmed by a study that demonstrated a major defect in myometrial spiral artery remodelling that was particularly prevalent when preeclampsia was accompanied by severe fetal growth restriction ${ }^{39}$.

Molecular mechanisms that mediate spiral artery remodelling are still being debated. Studies have shown that during normal placentation, cytotrophoblasts differentiate from an epithelial to an endothelial phenotype - a process that is referred to as 'pseudo-vasculogenesis' or 'vascular mimicry' — and that this transformation fails to occur in pre-eclampsia ${ }^{35,36}$. Cytotrophoblasts that do not invade the maternal spiral arterioles fail to express endothelial adhesion markers such as VE-cadherin and $a 1 \beta 1$ and $\alpha \mathrm{V} \beta 3$ integrin, which are expressed by normal invading cytotrophoblasts. These abnormalities in cytotrophoblast differentiation in the placentae of women with pre-eclampsia suggest that the mechanisms that contribute to placental ischaemia are set into motion very early in pregnancy. Thus, the concept of defective placentation and failure to transform uterine spiral arteries has emerged as central to the pathogenesis of pre-eclampsia.

Experimental investigations of placental metabolic profiles throughout gestation have shown that energy demands are uncompromised in the first trimester despite relative hypoxia ${ }^{40}$. Moreover, in human villous explants at 5-8 weeks, low oxygen tension triggered cytotrophoblast proliferation via mechanisms involving the transcription factor hypoxiainducible factor 1a (E1IF1a $)^{41}$. HIF1a and HIF2a are the products of a common oxygensensing pathway. They regulate the expression of hypoxia-induced genes including erythropoietin, vascular endothelial growth factor (VEGF) and nitric oxide (NO) synthase. Expression of HIF1a in human placentae is increased in the first trimester and decreases at around 9 weeks when circulation and thus oxygenation to the fetus increase ${ }^{41}$.

Persistently elevated HIF1a levels may indicate placental stress and herald the development of pre-eclampsia ${ }^{40}$. Indeed, pre-eclamptic placentae have been shown to overexpress HIF1a and HIF2 $a$ and fail to downregulate their expression upon oxygenation ${ }^{42}$. Furthermore, pregnant mice that overexpress HIF1a show several hallmarks of pre-eclampsia, including increased blood pressure, proteinuria, intrauterine growth restriction, glomerular endotheliosis, HELLP syndrome (haemolysis, elevated liver enzymes and low platelet count) and elevated levels of antiangiogenic factors such as soluble FFT1 (sFFT1; also known as sVEGFR1) and soluble endoglin (sENG $)^{43}$. Hypoxia-induced increases in the level of sFFT1 were demonstrated in both in vitro and in vivo models of placental hypoxia, including in placentae from early-first-trimester pregnancies in women living at high altitude and from women with pre-eclampsia ${ }^{44}$. Thus, HIFla seems to be a pathogenic mediator in preeclamptic pregnancies. The cause of persistently elevated expression of HIF in preeclamptic placentae remains unclear, but the upstream pathway of 2-methoxyoestradiol (2ME) generation by catechol- $O$-methyltransferase (COMT) has been implicated ${ }^{45}$. 2-ME is a metabolite of oestradiol that increases throughout pregnancy and destabilizes, and thus 
inhibits, HIFla. Current evidence is conflicting regarding the levels of placental expression of COMT in women with pre-eclampsia; some small studies have reported decreased placental COMT levels in hypertensive pregnancies, whereas others show no difference in COMT expression between hypertensive and normotensive pregnancies ${ }^{46,47}$. Farger clinical studies using robust assays that measure circulating 2-ME and other oestrogen metabolites should shed light on the role of the COMT pathway in pre-eclampsia.

Oxidative stress.-Oxidative stress also occurs at the maternal-fetal interface and is thought to have a key role in normal and defective placental development. Normal regression of the peripheral villi (where placental blood flow begins) early in gestation is postulated to occur via a mechanism involving oxidative stress and apoptosis ${ }^{48}$. In pre-eclampsia, an imbalance seems to exist between antioxidant and pro-oxidant mechanisms. This imbalance may be due to the defective spiral artery remodelling that is seen in affected pregnancies, which is thought to lead to repetitive ischaemia-reperfusion injuries owing to the retention of contractile segments of the spiral arteries in the myometrium ${ }^{38}$. Consistent with this hypothesis, in vitro studies showed increased levels of reactive oxygen species in human placental tissue after ischaemia and reperfusion ${ }^{49}$. These findings were further supported by a study that demonstrated increased oxidative stress in pregnant rats with reduced uterine perfusion pressure (a model of hypertensive pregnancy) $)^{50}$.

The haem oxygenase (HO) pathway is an important mediator of oxidative stress. $\mathrm{HO}$ exists as an inducible isoform (HO1), a constitutive isoform (HO2) and an isoform with unknown function $(\mathrm{HO} 3)^{51}$. $\mathrm{HO} 1$ and $\mathrm{HO} 2$ oxidize haem to produce biliverdin and carbon monoxide (CO). Biliverdin is converted to bilirubin, which has antioxidant effects including inhibition of LDL lipid oxidation, whereas CO is a signalling molecule with pleiotropic effects, including vasorelaxation and cardioprotection ${ }^{52}$. In 2000, a study demonstrated the importance of $\mathrm{HO} 1$ as an endogenous mediator of placental development and regulation ${ }^{53}$. Using transcriptional profiling and immunohistochemistry, the researchers showed that $\mathrm{HO} 1$ localized to the perivascular contractile sheath of human placental vessels and that its induction attenuated tumour necrosis factor (TNF)-mediated cellular damage. They also reported that the level of $\mathrm{HO} 1$ protein was substantially reduced in pre-eclamptic placentae compared with the placentae of normotensive controls ${ }^{53}$.

Interestingly, adenoviral overexpression of $\mathrm{HO} 1$ in endothelial cells inhibited placental release of antiangiogenic factors ${ }^{54}$, whereas induction of $\mathrm{HO} 1$ using cobalt protoporphyrin in an animal model of pre-eclampsia attenuated hypertension induced by placental ischaemia, suggesting a role of HO1 in the downstream effects of such ischaemia on the maternal endothelium ${ }^{55}$. Consistent with these findings, HO1-knockout mice had lower birthweights and litter sizes than normal controls, whereas HO1 heterozygotes had elevated maternal diastolic blood pressure and sFLT1 levels compared with wild-type pregnant mice despite compensatory increases in $\mathrm{HO} 2$ expression $^{56}$. Taken together, these findings support the role of the $\mathrm{HO}$ system as an important mediator of oxidative stress in normal pregnancy as well as a key factor in the pathogenesis of abnormal placentation in pre-eclampsia.

Endoplasmic reticulum (ER) stress has also been reported in the placental tissue obtained from patients with pre-eclampsia ${ }^{57,58}$. Further studies are needed to assess whether ER 
stress is a result of placental hypoxia or is a causative factor with a role in the development of the placentation abnormalities that occur in preeclampsia. Reduced expression of activating transcription factor 3 , which is highly expressed in the placenta, has been reported to contribute to pre-eclampsia by promoting aberrant placental expression of HIF and antiangiogenic factors ${ }^{59}$; however, the molecular nature of this dysfunction remains to be elucidated.

Immune mechanisms.-Elucidating the underlying cause of defective placentation warrants an understanding of the immunological tolerance that is required at the maternalplacental interface. Decidual natural killer (dNK) cells have a key role in spiral artery remodelling ${ }^{60}$. In vivo studies showed that injection of dNK cells into immunocompromised mice with elevated uterine artery resistance reduced this resistance, suggesting improved placentation ${ }^{61}$. Thus, appropriate activation of dNK cells is essential for normal placentation.

Another aspect of immunity that has been implicated in pre-eclampsia is the major histocompatibility complex (MHC). Normal fetal trophoblast cells express HLA-C molecules, which interact with killer Ig-like receptors (KIRs) expressed on maternal uterine natural killer cells ${ }^{62}$. HLA-C is inherited from both the mother and the father, and certain groups of HLA-C molecules, as well as certain haplotypes of KIRs, seem to be more frequently expressed in pre-eclamptic pregnancies than in normal pregnancies ${ }^{62}$. This finding suggests that normal placentation requires allorecognition by maternal KIRs of paternal HLA-C ${ }^{63}$ and that the increased incidence of pre-eclampsia with first pregnancies, changing paternity, shorter periods of sexual cohabitation and use of barrier contraception is related to reduced paternal antigen exposure ${ }^{64,65}$.

Normal placentation is also characterized by a characteristic profile of $\mathrm{T}$ cells and their respective cytokines, with a predominance of type $2 \mathrm{~T}$ helper cytokines (such as antiinflammatory IL-10) and suppression of the pro-inflammatory T-helper-1-type reaction by cytotoxic $\mathrm{T}$ cells to fetal trophoblasts ${ }^{66}$. By contrast, pre-eclampsia is characterized by an imbalance in the $\mathrm{T}$ cell profile, with a predominance of $\mathrm{T}$ helper 1 cells and their associated cytokines such as IFN $\gamma$ and $\mathrm{TNF}^{67}$. This imbalance likely contributes to poor placentation and the ensuing maternal inflammation and endothelial dysfunction.

Complement activation has been implicated in pathological pregnancies such as preeclampsia and intrauterine fetal growth restriction ${ }^{68}$. A 2006 study showed activation of complement, particularly the anaphylatoxin C5a, in an antibody-independent mouse model of spontaneous miscarriage and intrauterine growth restriction; both of these conditions are characterized by defective placentation ${ }^{69}$. Lynch et al. prospectively measured complement activation fragment $\mathrm{Bb}$, a marker of the alternative pathway, in human pregnancies before 20 weeks ${ }^{70}$. They found that women with Bb levels in the top decile were four times more likely to develop pre-eclampsia than those with lower levels. These findings provide compelling evidence for the involvement of complement in the pathogenesis of preeclampsia. In experimental models of pre-eclampsia, angiogenic factor imbalance seems to antedate complement activation ${ }^{71}$. It has been argued that complement activation is particularly critical in the development of severe cases of pre-eclampsia such as in HELLP 
syndrome ${ }^{72}$. Indeed, complement dysregulation occurs in atypical haemolytic uraemic syndrome, a thrombotic microangiopathy (TMA) with histological similarities to preeclampsia with severe features and HELLP syndrome ${ }^{73}$.

\section{Maternal syndrome}

The hallmarks of pre-eclampsia are not confined to the placenta but also extend to widespread effects in the mother that can be collectively viewed as the maternal syndrome (stage II; FIG. 1). On a histological level, the pathologic lesions of pre-eclampsia and eclampsia are characterized by widespread endothelial lesions in various organ beds ${ }^{74}$. An autopsy series of 317 mothers who died of eclampsia identified brain lesions with perivascular oedema in $68.4 \%$ of these women, haemorrhage in $36.8 \%$, haemosiderin in $31.6 \%$, small vessel thrombosis in $10.5 \%$, parenchymal necrosis in $15.8 \%$, liver lesions with periportal and portal necrosis and sinusoidal fibrin in $72.2 \%$ and hepatic arterial medial necrosis in $44.4 \%$. In this study, renal tissue demonstrated hallmarks of glomerular endotheliosis similar to those reported in previous studies ${ }^{75}$. Free radical formation was evident in areas of tissue injury and focally in intact neuronal elements.

Glomerular endotheliosis.-The term 'glomerular endotheliosis' was coined over four decades ago to describe light microscopy findings of glomeruli that are enlarged and 'bloodless' as a result of swollen endothelial and sometimes mesangial cells and occluded capillary lumens ${ }^{76}$ (FIG. 3). Thrombosis is a characteristic finding in most cases of TMA but is not typically seen in glomerular endotheliosis; however, severe pre-eclampsia with vascular thrombosis often suggests a superimposed non-pre-eclamptic TMA or HELLP syndrome ${ }^{76}$. The link between proteinuric pre-eclampsia and endotheliosis is not entirely clear. Electron microscopy of pre-eclamptic podocytes shows minimal foot process effacement and a minimal reduction in filtration slit frequency compared with normal podocytes ${ }^{76}$. Some evidence suggests that proteinuria might occur as a result of endothelial disruption alone perhaps due to loss of endothelial glycocalyx ${ }^{77}$. However, the podocyturia that has been noted during preeclampsia might also contribute to proteinuria ${ }^{78}$. Further work is needed to elucidate the precise mechanisms that underlie proteinuria in pre-eclampsia.

Imbalance in angiogenic factors.-Experimental and epidemiological studies support a pathological role for imbalance in circulating angiogenic factors in the aetiology of the maternal syndrome $e^{9,79,80}$. Excess levels of the antiangiogenic factor sFLT1, which is produced in the placenta and released into the maternal circulation, induce maternal endothelial dysfunction leading to preeclamptic signs and symptoms ${ }^{80-85}$. sFLT1 is a soluble splice variant of the membrane-bound receptor VEGFR1 that binds to the proangiogenic proteins VEGF and placental growth factor (PIGF); therefore, sFLT1 acts as a ligand trap and antagonizes ligand-mediated angiogenic signalling via the cell surface receptors ${ }^{79,86-88}$ (FIG. 4).

In rodents, sFLT1 overexpression produces symptoms of pre-eclampsia, and in humans higher maternal levels of sFLT1 are associated with more severe forms of the disease ${ }^{82,84,89-91}$. High plasma sFLT1:PIGF ratios are also strong predictors of disease severity and adverse clinical outcomes ${ }^{84,92-96}$. Drugs that inhibit angiogenic signalling such 
as the VEGF-neutralizing drugs bevacizumab (Avastin; Genentech) and VEGF-trap (aflibercept; Regeneron) and small-molecule inhibitors of VEGF receptors are associated with major adverse effects of pre-eclampsia-like symptoms including hypertension, proteinuria and renal glomerular changes ${ }^{97-100}$. Together, these findings indicate that high levels of circulating sFLT1 and low levels of circulating proangiogenic factors (VEGF and PlGF) produce an antiangiogenic state that contributes to the clinical manifestations of preeclampsiall.

Placental sFLT1 is heavily matrix bound, and the mechanisms by which it gains access to the systemic circulation were initially unclear ${ }^{101}$. However, syncytial fragments that shed into the maternal circulation have now been identified as an important source of circulating sFLT1 in pre-eclampsia ${ }^{102,103}$ as well as contributors to maternal endothelial dysfunction ${ }^{104}$. Further studies to characterize the molecular apparatus that drives the formation of the syncytium and enables the release of syncytiotrophoblast fragments may shed new light on the earliest mechanisms of pre-eclampsia.

The antiangiogenic protein sENG, which inhibits transforming growth factor- $\beta$ (TGF $\beta$ ) signalling, has also been studied extensively in pre-eclampsia ${ }^{82,84,87}$. sENG is expressed at high levels in pre-eclampsia and in eclampsia ${ }^{105,106}$. In rodents, overexpression of sENG and sFLT1 produced pre-eclampsia signs and symptoms that were more severe than those that were induced by either protein alone ${ }^{82,107}$. Similarly, elevated levels of both sENG and sFLT1 are also associated with more severe forms of pre-eclampsia in humans ${ }^{84,105}$. In mice, overexpression of sFLT and SENG interfered with endothelial cell stability and led to development of periventricular oedema that resembled the cerebral oedema that is seen in patients with eclampsia ${ }^{108}$. Exactly how sFLT1 synergizes with sENG to produce the severe phenotype is unknown; however, sENG may downregulate a TGF $\beta$ signalling pathway and further attenuate endothelial NO synthase (eNOS) activity, resulting in decreased NO availability and increased vascular permeability 82,84 .

Hypertension.-The hypertension that occurs in preeclampsia does not seem to be mediated through the renin-angiotensin-aldosterone system (RAAS) as the levels of renin, aldosterone and angiotensin II are reduced in affected pregnancies compared with their physiological increases in normal pregnancy ${ }^{109}$. Rather, this hypertension might be mediated via antiangiogenic factors and agonistic autoantibodies that bind to the angiotensin II type 1 receptor $(\mathrm{AT} 1-\mathrm{AAs})^{110,111}$. These autoantibodies develop in women with pre-eclampsia ${ }^{112}$, and when injected into pregnant mice, they induce hypertension, proteinuria and glomerular endotheliosis ${ }^{113}$. Levels of AT1-AAs do not fully regress postpartum and may contribute to the increased cardiovascular risk that is seen in women with a history of pre-eclampsia ${ }^{114}$. AT1-AAs have also been shown to upregulate sFLT1 in pregnant mice and induce fetal growth restriction ${ }^{115}$. Further studies are needed to evaluate the temporal relationship between AT1-AAs and antiangiogenic factor production in humans. Bradykinin (B2) receptor upregulation and heterodimerization of B2 receptors with angiotensin II type I receptors (AT1s), has also been hypothesized to contribute to increased responsiveness to angiotensin II and hypertension during pre-eclampsia ${ }^{116}$; however, definitive evidence for the existence of this pathway in humans is lacking. 
Another important mediator of endothelial dysfunction in pre-eclampsia is the potent vasodilator and antioxidant NO, which has been shown to mediate the effects of PlGF and VEGF in vitro ${ }^{111,117,118}$. Circulating levels of NO are reduced in women with preeclampsia ${ }^{119-121}$, whereas restoration of bioavailable NO seems to attenuate the elevation in sFLT1 and hypertension that is seen in pregnant rats with NO synthesis inhibition ${ }^{122}$. Polymorphisms and changes in the expression of eNOS have also been implicated in preeclamptic pregnancies ${ }^{123}$.

Endothelin 1 (ET1) is a potent vasoconstrictor, and the hypertension and renal injury that occur as a result of VEGF blockade have been shown to be mediated through activation of the ET system ${ }^{124}$. Levels of ET1 are elevated in women with pre-eclampsia ${ }^{109}$, and ET1 production has been shown experimentally to mediate the hypertension that is caused by sFLT1 and AT1-AAs ${ }^{125}$. As ET1 blockers cross the placenta, ET1 signalling has remained less attractive than other potential therapeutic targets for pre-eclampsia ${ }^{126}$.

The hydrogen sulfide $\left(\mathrm{H}_{2} \mathrm{~S}\right)$ system is another key mechanistic pathway in vasodilation and angiogenesis. Decreased circulating levels of $\mathrm{H}_{2} \mathrm{~S}$ have been demonstrated in women with pre-eclampsia, as has reduced placental expression of cystathionine $\gamma$-lyase, which is the enzyme that is responsible for $\mathrm{H}_{2} \mathrm{~S}$ production ${ }^{127}$. The effects of $\mathrm{H}_{2} \mathrm{~S}$ in pregnancy may be mediated through VEGF, as administration of the $\mathrm{H}_{2} \mathrm{~S}$ donor sodium hydrosulfide (NaHS) to sFLT1-overexpressing rats attenuated hypertension, proteinuria and glomerular endotheliosis $^{128}$. Furthermore, increased levels of VEGF were seen with NaHS treatment, whereas addition of a neutralizing antibody to VEGF receptor 2 attenuated NaHS-induced vasodilation. NaHS has also been shown to reduce hypertension, proteinuria and oxidative stress in a hypertensive rat model utilizing angiotensin II infusion, further supporting the role of $\mathrm{H}_{2} \mathrm{~S}$ as a key mediator of vasodilation and endothelial function ${ }^{129}$.

Endothelial dysfunction.-The concept of a maternal predisposition to pre-eclampsia has been posited and supported by extensive work done at the vascular level of affected mothers. As early as the 1970s, increased responsiveness to vasopressors was demonstrated in women with hypertension in pregnancy ${ }^{130}$. This responsiveness may be augmented by circulating sFLT1 (REF. ${ }^{111}$ ). Increased responsiveness to vasopressors has now been shown to continue postpartum, with women with a history of hypertensive pregnancy showing increased blood pressure, aldosterone levels and sFLT1 levels in response to these agents ${ }^{131}$.

Germain et al. suggested that abnormal endothelial function as evidenced by reduced vasodilation, decreased circulating NO and increased cholesterol levels may precede pregnancy in women who later develop pre-eclampsia ${ }^{132}$. This hypothesis is supported by that fact that such endothelial dysfunction is also present in women with recurrent miscarriage, who have an increased risk of future CVD despite an absence of the hypertension and end-organ damage that are seen in pre-eclampsia ${ }^{132}$. Thus, endothelial dysfunction before pregnancy may be a common link between conditions with defective placentation and CVD. Indeed, evidence suggests that in pre-eclampsia, progenitor endothelial cells do not display the physiological increase in the maternal circulation that occurs in normal pregnancy ${ }^{133}$. 
Obesity, insulin resistance and other factors.-Extensive research has focused on obesity and insulin resistance in normal and pre-eclamptic pregnancies ${ }^{134}$. Normal pregnancy is characterized by relative insulin resistance and hyperinsulinaemia, which is thought to divert appropriate nutrition to the developing fetus ${ }^{135}$. Consistent with this hypothesis, disorders characterized by defective placentation can result in small-forgestational-age fetuses ${ }^{136}$. Pre-eclampsia is associated with increased hyperinsulinaemia ${ }^{137,138}$, abnormal placental glycogen accumulation ${ }^{139}$ and impaired placental insulin signalling ${ }^{140}$. Insulin resistance seems to act synergistically with impaired angiogenic factors to induce increased risk of pre-eclampsia ${ }^{141}$.

In addition, excess vasopressin has been implicated in the maternal disease in animal models of pre-eclampsia ${ }^{142}$. In clinical settings characterized by excess vasopressin, water excretion by the kidneys is substantially impaired, leading to severe hyponatraemia. However, hyponatraemia is not a typical feature of human pre-eclampsia. More evidence in patients with pre-eclampsia is required to ascribe a precise role for vasopressin in disease pathophysiology.

\section{Novel biomarkers}

Angiogenic factors have emerged as important biomarkers in pre-eclampsia, and in our opinion, imbalance of these angiogenic markers is central to the pathogenesis of the maternal syndrome ${ }^{143}$. In four independent human studies, we demonstrated that most of the complications of pre-eclampsia or pre-eclampsia-related delivery can be explained by alterations in angiogenic pathways ${ }^{94,144-146}$. The levels of PlGF, sFLT1 and sENG, as well as the ratios of sFLT1 to PIGF and PIGF to sENG, differ significantly between women with preeclampsia and those with normotensive pregnancies, with especially good predictive performance in early-onset disease ${ }^{147-150}$. The levels of these factors might also differentiate between mild pre-eclampsia with delivery at term and severe disease with preterm delivery ${ }^{148}$. Changes in the levels of sENG and sFLT1 between the first and second trimesters were predictive of preterm pre-eclampsia ${ }^{151}$, whereas third-trimester levels could identify those women who were at risk of severe late disease and stillbirth ${ }^{152}$.

The levels of angiogenic factors correlate with severity of disease; a 2004 study showed that median plasma sFLT1 levels were higher in patients with early-onset and severe disease than in those with late-onset and mild disease ${ }^{153}$. Changes in the levels of PIGF and sFLT1 have been detected as early as 6-10 weeks before the onset of clinical pre-eclampsia, and these changes occurred earlier in women who developed preterm pre-eclampsia ${ }^{154,155}$. Many studies have confirmed that levels of sFLT1 and PIGF in the triage setting can be used as a robust prognostic test, and these levels correlate with the duration of pregnancy in patients with early-onset preclampsia $95,96,150,156$.

A landmark multicentre clinical trial demonstrated that the sFLT1:PIGF ratio can be used to rule out preeclampsia over a 1-week period among patients with suspected disease, with a negative predictive value $>99 \%{ }^{157}$. In a post hoc analysis of these data, the negative predictive value to rule out pre-eclampsia occurring within 4 weeks from presentation was $\sim 95 \%{ }^{158}$. The improved diagnostic and prognostic capabilities that are provided by levels of 
angiogenic markers render them useful tools for triage and avoidance of unnecessary expense. In a study that used angiogenic markers for diagnosis and management, the resulting decrease in the number of women who were falsely identified as positive for preeclampsia led to a potential average per-patient cost reduction of US $\$ 1,215$ owing to the avoidance of unnecessary tests and admissions ${ }^{159}$. Another study that used a decisionanalytic model to simulate 1,000 pregnant women receiving standard obstetric care in the UK and estimate the economic impact of using angiogenic markers rather than standard diagnostic tests reported an estimated saving of $£ 945$ per patient ${ }^{160}$. The true value of such tests remains to be seen with further application in clinical practice.

Angiogenic biomarkers are also useful in differentiating pre-eclampsia from other diseases that may manifest in pregnancy with similar signs and symptoms, such as CKD, gestational thrombocytopenia and chronic hypertension, and thus could replace invasive renal biopsy for diagnostic purposes ${ }^{161-165}$. Management of pregnancy in lupus is particularly challenging, and angiogenic markers have been found to have a role in screening for superimposed preeclampsia in these patients ${ }^{166}$. A study that included nearly 500 pregnant women with lupus and/or antiphospholipid antibody syndrome showed that circulating levels of sENG, PIGF and particularly sFLT1 were significantly higher in those patients who developed severe adverse outcomes, including early-onset pre-eclampsia, fetal demise and preterm delivery ${ }^{167,168}$. Adverse outcomes reportedly affect over $20 \%$ of pregnancies in women with lupus and/or antiphospholipid antibody syndrome ${ }^{169}$; therefore, the identification of those who are at highest risk would provide invaluable information for the managing clinician.

Circulating angiogenic factors have been evaluated as a screening tool to predict onset of pre-eclampsia ${ }^{170}$. In a large UK study, the plasma sFLT1:PIGF ratio measured at midtrimester ( 28 weeks) had a positive predictive value of $32 \%$ for preterm pre-eclampsia in a cohort of unselected nulliparous women $(n=4,099)^{171}$. Angiogenic markers have also been incorporated into several first-trimester prediction models that use maternal characteristics as well as biophysical and biochemical markers. In women with singleton pregnancies, a first-trimester algorithm that combined the logs of uterine pulsatility index, mean arterial pressure, pregnancy associated plasma protein A, serum free PlGF, body mass index and the presence of nulliparity or previous pre-eclampsia had a detection rate for early-onset preeclampsia of $93.1 \%$ with a false-positive rate of $5 \%{ }^{172}$. A clinical trial that reported that aspirin prophylaxis early in pregnancy was highly effective for prevention of pre-eclampsia used an algorithm containing biophysical and angiogenic risk factors to identify patients at risk of preterm pre-eclampsia for enrolment; this trial is discussed further below ${ }^{173}$.

Current research is exploring the use of proteomic studies using mass spectrometry and protein microarray, urinary proteomics and metabolomics for the detection and prognostication of pre-eclampsia ${ }^{174-179}$. Fetal RNA levels have been found to be tenfold higher in women with pre-eclampsia than in those with normal pregnancies and are being explored together with placental RNA as useful biomarkers for the early detection of preeclampsia ${ }^{180-183}$. 


\section{Novel therapeutic strategies}

Several novel strategies to treat the clinical signs of pre-eclampsia and prolong gestation are being investigated ${ }^{9}$. These strategies include injection of recombinant proteins such as VEGF or PIGF, inhibition of sFLT1 production via small molecules and RNA interference (RNAi) and selective depletion of circulating sFLT1 with antibodies and extracorporeal devices.

\section{sFLT1 ligands}

VEGF is the natural ligand for sFLT1, and recombinant VEGF121, which is a novel nonheparin-binding isoform of VEGF, has been tested as a potential therapy for pre-eclampsia in pregnant rats overexpressing sFLT1 $\left(\right.$ REF. $\left.{ }^{90}\right)$. VEGF121 treatment attenuated hypertension and renal damage in these rats without adverse effects on the fetus. Similar attenuation of the effects of sFLT1 were seen in mice treated with VEGF-containing adenovirus ${ }^{184}$. Infusion of VEGF121 also lowered blood pressure and preserved renal function in a reduced uterine pressure model of pre-eclampsia in rats ${ }^{185}$, and beneficial effects of VEGF121 have been confirmed in other models of pre-eclampsia ${ }^{186}$.

The efficacy of recombinant PIGF, another ligand of sFLT1, has been studied in rodent and primate models of pre-eclampsia ${ }^{187,188}$. In a primate model, PIGF treatment reduced blood pressure and proteinuria in comparison with non-treated pre-eclamptic controls ${ }^{182}$.

Similarly, PIGF treatment ameliorated elevated blood pressure and sFLT1 levels in a rodent pre-eclampsia model ${ }^{183}$. The advantage of recombinant PlGF compared with VEGF is that PIGF does not bind to VEGFR2 and therefore does not induce the adverse effects that are associated with VEGFR2 activation such as vascular permeability and oedema. Relaxin, a novel, pregnancy-specific, proangiogenic protein made by the corpus luteum, is also being evaluated as a potential therapeutic for pre-eclampsia, with rodent studies demonstrating lower blood pressure and improved uterine perfusion in pre-eclamptic rats after treatment with relaxin when compared with pre-eclamptic controls ${ }^{189}$.

\section{RNA interference-based strategies}

Small interfering RNA (siRNA)-based therapies use RNA silencing molecules to stop the production of specific cellular proteins. RNA sequencing studies in human placentae from pre-eclamptic pregnancies suggest that three major isoforms of the FLT1 locus contribute to sFLT1 in the circulation ${ }^{190}$. In 2018, researchers identified novel RNAi molecules that specifically target all of the major sFLT1 mRNAs in cell culture studies ${ }^{191}$. They demonstrated that a single dose of sFLT1 RNAi therapy given intravenously lowered the sFLT1 protein level by $50 \%$, which was accompanied by a reduction in blood pressure and proteinuria in a baboon model of pre-eclampsia. As the cost of production of oligonucleotide therapies is substantially less expensive than that of recombinant proteins, this strategy may prove to be particularly useful in developing countries where pre-eclampsia is associated with very high morbidity. 


\section{Small-molecule inhibitors}

Sildenafil is a phosphodiesterase 5 inhibitor that enhances cGMP signalling. This agent has been shown to lower blood pressure and enhance fetal growth in various rodent models of pre-eclampsia ${ }^{192}$. These findings are not surprising given the high dependency of the uterine circulation on NO signalling and the importance of NO in the cGMP signalling pathway ${ }^{193}$. In a small clinical study in women with pre-eclampsia, sildenafil therapy prolonged pregnancy duration by 4 days and lowered blood pressure ${ }^{194}$. However, the STRIDER study, a multicentre trial of sildenafil to treat early-onset growth restriction, was terminated early owing to higher-than-expected rates of fetal lung disease and death in the intervention group ${ }^{195,196 .}$

Placental hypoxia is central to the pathogenesis of pre-eclampsia, and ouabain, a digoxinlike molecule that inhibits HIF1 and HIF2, was shown to block sFLT1 production and reduce hypertension in rats with placental ischaemia ${ }^{197}$. Use of metformin (an insulin sensitizer that is approved for use in type 2 diabetes mellitus) during pregnancy is associated with a reduced incidence of pre-eclampsia ${ }^{198}$. Metformin has been shown to reduce the production of antiangiogenic factors in vitro ${ }^{199}$; however, prospective clinical trial data for metformin use in preventing pre-eclampsia are lacking.

Proton pump inhibitors (PPIs) were shown to block sFLT1 production in cell culture studies and to reverse hypertension in sFLT1-transgenic mice ${ }^{154}$. However, a large double-blind, placebo-controlled trial that evaluated the efficacy of the PPI esomeprazole for the treatment of early-onset pre-eclampsia was unable to show either prolongation of pregnancy or decreased sFLT1 evels ${ }^{200}$. Strategies that combine esomeprazole with other therapies such as metformin might prove to be more beneficial than use of esomeprazole alone ${ }^{201}$.

\section{Apheresis}

Removal of excess antiangiogenic proteins using extracorporeal methods is an attractive therapeutic strategy for pre-eclampsia as this approach avoids exposure of the fetus to potentially harmful drugs. For many years, apheresis has been used to treat pregnant women, including mothers with familial hypercholesterolaemia, without adverse effects on the mother or the fetus, demonstrating the safety of this approach ${ }^{202}$.

We used a dextran-sulfate apheresis (DSA) column that was marketed for LDL removal to reduce sFLT1 levels through nonspecific interactions between the negatively charged DSA column and the net positive charge of the sFLT1 protein $^{203}$. We reported that use of this apheresis treatment in women with preterm ( $<32$ weeks) pre-eclampsia was safe, reduced sFLT1 levels and had varying but generally positive effects, including reductions in proteinuria, stabilization of blood pressure and extended gestation ${ }^{203,204}$ (FIG. 5). The treated mothers experienced improvements in their symptoms, the newborn babies were healthy and both mothers and infants remained healthy at 1-year follow-up ${ }^{204}$. Unfortunately, sFLT1 removal using DSA columns is not efficient or selective, and these columns remove other plasma components such as fibrinogen, some of which may be essential during pregnancy. To circumvent these issues, adsorption columns using monoclonal antibodies to more selectively deplete sFLT1 are currently being developed. 


\section{Aspirin}

Several common therapeutics, such as antioxidants and heparin, have been investigated for potential beneficial effects in pre-eclampsia without much success ${ }^{205,206}$. Aspirin treatment initiated at $\geq 16$ weeks gestation was, however, associated with an $-50 \%$ reduction in preterm pre-eclampsia with a dose-dependent effect in six studies that included $-2,200$ women ${ }^{207}$. A clinical trial that enrolled 1,776 patients with low first-trimester PIGF levels reported that aspirin therapy at a dose of $150 \mathrm{mg}$ per day led to a $62 \%$ reduction in preterm pre-eclampsia compared with placebo ${ }^{173}$. Although definitive studies demonstrating beneficial effects of aspirin therapy on perinatal morbidity and mortality are still lacking, low-dose aspirin is now recommend for pre-eclampsia prophylaxis in women at high risk ${ }^{6,208}$.

\section{Antioxidants}

Clinical trials using nonspecific antioxidants such as vitamin $\mathrm{C}$ and vitamin $\mathrm{E}$ have not shown efficacy in preventing pre-eclampsia ${ }^{205,209}$. Interest is therefore increasing in characterizing the source of oxidative stress in preeclampsia to further define the therapeutic target. Oxidative stress arising from the mitochondria has emerged as an attractive target, and the use of mitochondrial-targeted antioxidants is now being investigated as a strategy to reverse oxidative stress in pre-eclampsia ${ }^{210,211}$.

\section{Statins}

Statin therapy has been shown to improve vascular function via stimulation of $\mathrm{HO} 1$ expression, which leads to enhanced NO synthase and decreased placental production of SFLT1 (REFS ${ }^{212,213}$ ). Statins have been used in several animal models of pre-eclampsia with promising results ${ }^{214-217}$. Some case reports in patients with severe pre-eclampsia suggest that pravastatin use might attenuate disease ${ }^{218-220}$. In patients with antiphospholipid antibody syndrome, which is often complicated by preeclampsia and fetal growth restriction, pravastatin was shown to prevent maternal and fetal adverse outcomes ${ }^{221}$. The StAmP double-blind, randomized, multicentre trial of pravastatin therapy in early-onset preeclampsia is currently underway (ISRCTN23410175) $)^{213}$. In the USA, a pilot study demonstrated a favourable angiogenic profile with no major toxic effects of pravastatin in high-risk pregnant women ${ }^{222}$. Further studies are needed to enable definitive conclusions to be drawn regarding the role of statins in preventing or treating pre-eclampsia.

\section{Long-term maternal and fetal outcomes}

Growing evidence indicates an increased risk of longterm adverse health outcomes in women affected by pre-eclampsia ${ }^{223}$. The risk of CVD seems to be particularly increased in affected mothers ${ }^{224}$, and the American Heart Association now recommends a pregnancy history as part of the cardiovascular risk evaluation of women ${ }^{225}$. A 2007 meta-analysis that included nearly 200,000 cases of pre-eclampsia showed relative risks of 3.7, 2.16 and 1.81 for hypertension, ischaemic heart disease and stroke, respectively, after a mean of 10-15 years of follow-up ${ }^{226}$. A subsequent meta-analysis showed a threefold increased risk of chronic hypertension and twofold increased risks of CVD and stroke in mothers affected by pre-eclampsia in comparison with those with normotensive pregnancies ${ }^{227}$. Women who had experienced a pregnancy that was complicated by early-onset pre-eclampsia also showed 
increased risk of CVD risk factors, including increased levels of fasting blood glucose, insulin, triglycerides and total cholesterol, compared with women who had experienced lateonset pre-eclampsia or gestational hypertension ${ }^{228}$. The prevalence of metabolic syndrome was also shown to be increased by twofold in women with a history of preeclampsia compared with women with a history of small-for-gestational-age babies ${ }^{229}$. Currently, the ACOG Task Force recommends periodic assessment of blood pressure, lipids, fasting blood glucose and body mass index in women who have a history of preterm or recurrent preeclampsia ${ }^{6}$.

Pre-eclampsia is also associated with an excess of peripartum cardiomyopathy ${ }^{230}$. Experimental studies in rodents suggest that the antiangiogenic milieu during pre-eclampsia is a key risk factor for the development of this disease ${ }^{231}$. A study of echocardiographic findings and angiogenic markers in women with pre-eclampsia suggested that myocardial dysfunction during preeclampsia correlated with levels of angiogenic markers, such as sFLT1 and $\mathrm{sENG}^{232}$.

The incidence of CKD and end-stage renal disease (ESRD) is also increased in women with a history of pre-eclampsia. A 2008 retrospective analysis that used databases containing data on all births since 1967 and all incident ESRD diagnoses since 1980 in Norway showed a modest but significantly increased risk of subsequent ESRD in women with a history of prior pre-eclampsia ${ }^{233}$. A subsequent meta-analysis showed a fourfold increased risk of microalbuminuria at a mean of 7.1 years postpartum in women with pre-eclampsia and an eightfold increased risk of microalbuminuria in those who had previously experienced preeclampsia with severe features ${ }^{234}$. Conversely, the risks of adverse pregnancy outcomes and pre-eclampsia are increased in women with CKD or a history of acute kidney injury, even after a return to apparently normal renal function ${ }^{235,236 .}$

Pre-eclampsia and CVD share many common risk factors, such as chronic hypertension and obesity. Whether the long-term CVD risks that are associated with pre-eclampsia result from persistent vascular damage that is induced during the affected pregnancy or simply reflect common pre-existing risk factors that are shared by pre-eclampsia and CVD is unknown. Experimental studies in pregnant mice support the hypothesis that pre-eclampsia results in direct changes to vascular physiology that increase the response to future vascular damage 237,238 .

Pre-eclampsia is also an important risk factor for neonatal respiratory distress syndrome and bronchopulmonary dysplasia ${ }^{239,240}$; however, the mechanisms that underlie these associations are unclear. Studies have suggested that bronchopulmonary dysplasia is characterized by impaired angiogenesis in the fetal lung ${ }^{241}$. In human pre-eclampsia, sFLT1 levels in amniotic fluid are markedly elevated in parallel with maternal serum concentrations ${ }^{127,242}$. In pregnant rats, intra-amniotic sFLT1 treatment in late gestation led to bronchopulmonary dysplasia and pulmonary hypertension ${ }^{243}$. These studies suggest a novel molecular target and strategy for the prevention of bronchopulmonary dysplasia. Preeclampsia is also associated with reduced risk of retinopathy of prematurity, which is a disorder of angiogenesis ${ }^{244}$. Whether this protection is related to an antiangiogenic environment during pre-eclampsia is unknown. 


\section{Conclusions}

Pre-eclampsia is a serious condition that has complicated pregnancies for centuries. The prevalence of preeclampsia varies considerably by region, but this disease remains a universal health concern. Many risk factors for pre-eclampsia exist, reflecting the contributions of underlying immune mechanisms and the maternal constitution to its development. Diagnostic criteria for the condition have expanded to reflect the heterogeneity of clinical presentation and the systemic nature of the disease. The underlying pathogenesis is not fully unravelled but is understood to originate in an ischaemic placenta, with release of antiangiogenic factors into the maternal circulation and ensuing maternal endothelial dysfunction and multi-organ failure.

Angiogenic imbalance is a hallmark of pre-eclampsia, and angiogenic markers have proved to be effective tools for early diagnosis and prognosis of affected pregnancies. The only effective treatment for pre-eclampsia remains delivery, but novel therapies are being developed to ameliorate complications and prolong gestation. Aspirin has been recommended as a preventive therapy for preterm pre-eclampsia, and statins are being explored as another potential intervention. In the future, restoring angiogenic balance, either by administering proangiogenic factors or removing antiangiogenic factors, may prove to be an effective strategy for extending pregnancies with preterm pre-eclampsia.

Emerging research has shown that pre-eclampsia has long-term health consequences for the mother and fetus, with significantly increased risk of CVD and CKD in the mother. Further study of the causes of these associations and of targeted therapies for pre-eclampsia is warranted.

\section{Acknowledgements}

The authors thank I. Stillman at the Department of Pathology, Beth Israel Deaconess Medical Center, USA, for providing the histology image used in figure 3.

\section{References}

1. Wallis AB, Saftlas AF, Hsia J \& Atrash HK Secular trends in the rates of preeclampsia, eclampsia, and gestational hypertension, United States, 1987-2004. Am. J. Hypertens 21, 521-526 (2008). [PubMed: 18437143]

2. Duley L The global impact of pre-eclampsia and eclampsia. Semin. Perinatal 33, 130-137 (2009).

3. Ananth CV, Keyes KM \& Wapner RJ Pre-eclampsia rates in the United States, 1980-2010: ageperiod-cohort analysis. BMJ 347, f6564 (2013).

4. Abalos E, Cuesta C, Grosso AL, Chou D \& Say L Global and regional estimates of preeclampsia and eclampsia: a systematic review. Eur. J. Obstet. Gynecol. Reprod. Biol 170, 1-7 (2013). [PubMed: 23746796]

5. Kuklina EV, Ayala C \& Callaghan WM Hypertensive disorders and severe obstetric morbidity in the United States. Obstet. Gynecol 113, 1299-1306 (2009). [PubMed: 19461426]

6. Task Force on Hypertension in Pregnancy. Report of the American College of Obstetricians and Gynecologists' Task Force on hypertension in pregnancy. Obstet. Gynecol 122, 1122-1131 (2013). [PubMed: 24150027] This paper highlights changes in diagnostic criteria for pre-eclampsia and summarizes the current recommendations for the management of patients with pre-eclampsia.

7. Bell MJ A historical overview of preeclampsia-eclampsia. J. Obstet. Gynecol. Neonatal Nurs 39, 510-518 (2010). 
8. Roberts JM et al. Preeclampsia: an endothelial cell disorder. Am. J. Obstet. Gynecol 161, 12001204 (1989). [PubMed: 2589440]

9. Karumanchi SA Angiogenic factors in preeclampsia: from diagnosis to therapy. Hypertension 67 , 1072-1079 (2016). [PubMed: 27067718]

10. Hod T, Cerdeira AS \& Karumanchi SA Molecular mechanisms of preeclampsia. Cold Spring Harb. Perspect. Med 5, a023473 (2015). [PubMed: 26292986]

11. Romero R \& Chaiworapongsa T Preeclampsia: a link between trophoblast dysregulation and an antiangiogenic state. J. Clin. Invest 123, 2775-2777 (2013). [PubMed: 23934119]

12. Ghulmiyyah L \& Sibai B Maternal mortality from preeclampsia/eclampsia. Semin. Perinatol 36, 56-59 (2012). [PubMed: 22280867]

13. Shahul S et al. Racial disparities in comorbidities, complications, and maternal and fetal outcomes in women with preeclampsia/eclampsia. Hypertens. Pregnancy 34, 506-515 (2015). [PubMed: 26636247]

14. Lo JO, Mission JF \& Caughey AB Hypertensive disease of pregnancy and maternal mortality. Curr. Opin. Obstet. Gynecol 25, 124-132 (2013). [PubMed: 23403779]

15. Zhang J, Meikle S \& Trumble A Severe maternal morbidity associated with hypertensive disorders in pregnancy in the United States. Hypertens. Pregnancy 22, 203-212 (2003). [PubMed: 12909005]

16. Robillard PY, Dekker G, Iacobelli S \& Chaouat G An essay of reflection: why does preeclampsia exist in humans, and why are there such huge geographical differences in epidemiology? J. Reprod. Immunol 114, 44-47 (2016). [PubMed: 26253618]

17. Lisonkova S \& Joseph KS Incidence of preeclampsia: risk factors and outcomes associated with early-versus late-onset disease. Am. J. Obstet. Gynecol 209, 544. e1-544.e12 (2013). [PubMed: 23973398]

18. Rasmussen S, Irgens LM \& Espinoza J Maternal obesity and excess of fetal growth in preeclampsia. BJOG 121, 1351-1357 (2014). [PubMed: 24589129]

19. Chaiworapongsa $T$ et al. Differences and similarities in the transcriptional profile of peripheral whole blood in early and late-onset preeclampsia: insights into the molecular basis of the phenotype of preeclampsiaa. J. Perinat. Med 41, 485-504 (2013). [PubMed: 23793063]

20. Hutcheon JA, Lisonkova S \& Joseph KS Epidemiology of pre-eclampsia and the other hypertensive disorders of pregnancy. Best Pract. Res. Clin. Obstet. Gynaecol 25, 391-403 (2011). [PubMed: 21333604]

21. Bartsch E, Medcalf KE, Park AL \& Ray JG \& High Risk of Pre-eclampsia Identification Group. Clinical risk factors for pre-eclampsia determined in early pregnancy: systematic review and metaanalysis of large cohort studies. BMJ 353, i1753 (2016). [PubMed: 27094586]

22. Bdolah Y et al. Circulating angiogenic proteins in trisomy 13. Am. J. Obstet. Gynecol 194, 239245 (2006). [PubMed: 16389038]

23. Skjaerven $\mathrm{R}$ et al. Recurrence of pre-eclampsia across generations: exploring fetal and maternal genetic components in a population based cohort. BMJ 331, 877 (2005). [PubMed: 16169871]

24. Heyborne K Paternal and maternal components of the predisposition to preeclampsia. N. Engl. J. Med 345, 149; author reply 150 (2001).

25. Mogren I, Hogberg U, Winkvist A \& Stenlund H Familial occurrence of preeclampsia. Epidemiology 10, 518-522 (1999). [PubMed: 10468424]

26. Gray KJ, Saxena R \& Karumanchi SA Genetic predisposition to preeclampsia is conferred by fetal DNA variants near FLT1, a gene involved in the regulation of angiogenesis. Am. J. Obstet. Gynecol 218, 211-218 (2018). [PubMed: 29138037]

27. McGinnis R et al. Variants in the fetal genome near FLT1 are associated with risk of preeclampsia. Nat. Genet 49, 1255-1260 (2017). [PubMed: 28628106] This large clinical genome-wide association study suggests that dysregulation at the FLT1 locus in the fetal genome (likely in the placenta) is a fundamental molecular defect in pre-eclampsia.

28. Goel A et al. Epidemiology and mechanisms of de novo and persistent hypertension in the postpartum period. Circulation 132, 1726-1733 (2015). [PubMed: 26416810]

29. Acosta-Sison H The relationship of hydatidiform mole to pre-eclampsia and eclampsia; a study of 85 cases. Am. J. Obstet. Gynecol 71, 1279-1282 (1956). [PubMed: 13313644] 
30. Hecht JL, Zsengeller ZK, Spiel M, Karumanchi SA \& Rosen S Revisiting decidual vasculopathy. Placenta 42, 37-43 (2016). [PubMed: 27238712]

31. Brosens I, Robertson WB \& Dixon HG The physiological response of the vessels of the placental bed to normal pregnancy. J. Pathol. Bacteriol 93, 569-579 (1967). [PubMed: 6054057]

32. Young $\mathrm{J}$ The aetiology of eclampsia and albuminuria and their relation to accidental haemorrhage: (an anatomical and experimental investigation). Proc. R. Soc. Med 7, 307-348 (1914).

33. Robertson WB, Brosens I \& Dixon HG The pathological response of the vessels of the placental bed to hypertensive pregnancy. J. Pathol. Bacteriol 93, 581-592 (1967). [PubMed: 6054058]

34. Brosens IA, Robertson WB \& Dixon HG The role of the spiral arteries in the pathogenesis of preeclampsia. Obstet. Gynecol. Annu 1, 177-191 (1972). [PubMed: 4669123]

35. Zhou Y et al. Human cytotrophoblasts adopt a vascular phenotype as they differentiate. A strategy for successful endovascular invasion? J. Clin. Invest 99, 2139-2151 (1997). [PubMed: 9151786]

36. Zhou Y, Damsky CH \& Fisher SJ Preeclampsia is associated with failure of human cytotrophoblasts to mimic a vascular adhesion phenotype. One cause of defective endovascular invasion in this syndrome? J. Clin. Invest 99, 2152-2164 (1997). [PubMed: 9151787] This paper demonstrates for the first time that invasive cytotrophoblasts fail to acquire endothelial markers in women with pre-eclampsia.

37. Meekins JW, Pijnenborg R, Hanssens M, McFadyen IR \& van Asshe A A study of placental bed spiral arteries and trophoblast invasion in normal and severe pre-eclamptic pregnancies. Br. J. Obstet. Gynaecol 101, 669-674 (1994). [PubMed: 7947500]

38. Burton GJ, Woods AW, Jauniaux E \& Kingdom JC Rheological and physiological consequences of conversion of the maternal spiral arteries for uteroplacental blood flow during human pregnancy. Placenta 30, 473-482 (2009). [PubMed: 19375795]

39. Lyall F, Robson SC \& Bulmer JN Spiral artery remodeling and trophoblast invasion in preeclampsia and fetal growth restriction: relationship to clinical outcome. Hypertension 62, 10461054 (2013). [PubMed: 24060885]

40. Cindrova-Davies T et al. Energy status and HIF signalling in chorionic villi show no evidence of hypoxic stress during human early placental development. Mol. Hum. Reprod 21, 296-308 (2015). [PubMed: 25391298]

41. Caniggia I et al. Hypoxia-inducible factor-1 mediates the biological effects of oxygen on human trophoblast differentiation through TGFbeta(3). J. Clin. Invest 105, 577-587 (2000). [PubMed: 10712429]

42. Rajakumar A, Doty K, Daftary A, Harger G \& Conrad KP Impaired oxygen-dependent reduction of HIF-1alpha and -2alpha proteins in pre-eclamptic placentae. Placenta 24, 199-208 (2003). [PubMed: 12566247]

43. Tal R et al. Effects of hypoxia-inducible factor-1alpha overexpression in pregnant mice: possible implications for preeclampsia and intrauterine growth restriction. Am. J. Pathol 177, 2950-2962 (2010). [PubMed: 20952590]

44. Nevo $\mathrm{O}$ et al. Increased expression of sFlt-1 in in vivo and in vitro models of human placental hypoxia is mediated by HIF-1. Am. J. Physiol. Regul. Integr. Comp. Physiol 291, R1085-R1093 (2006). [PubMed: 16627691]

45. Kanasaki K et al. Deficiency in catechol-O-methyltransferase and 2-methoxyoestradiol is associated with pre-eclampsia. Nature 453, 1117-1121 (2008). [PubMed: 18469803]

46. Barnea ER, MacLusky NJ, DeCherney AH \& Naftolin F Catechol-o-methyl transferase activity in the human term placenta. Am. J. Perinatol 5, 121-127 (1988). [PubMed: 3348855]

47. Palmer $\mathrm{K}$ et al. Severe early-onset preeclampsia is not associated with a change in placental catechol O-methyltransferase (COMT) expression. Am. J. Pathol 178, 2484-2488 (2011). [PubMed: 21531374]

48. Burton GJ \& Jauniaux E Oxidative stress. Best Pract. Res. Clin. Obstet. Gynaecol 25, 287-299 (2011). [PubMed: 21130690]

49. Hung TH, Skepper JN \& Burton GJ In vitro ischemia-reperfusion injury in term human placenta as a model for oxidative stress in pathological pregnancies. Am. J. Pathol 159, 1031-1043 (2001). [PubMed: 11549595] 
50. Sedeek M et al. Role of reactive oxygen species in hypertension produced by reduced uterine perfusion in pregnant rats. Am. J. Hypertens 21, 1152-1156 (2008). [PubMed: 18670418]

51. Wu L \& Wang R Carbon monoxide: endogenous production, physiological functions, and pharmacological applications. Pharmacol. Rev 57, 585-630 (2005). [PubMed: 16382109]

52. Neuzil J \& Stocker R Free and albumin-bound bilirubin are efficient co-antioxidants for alphatocopherol, inhibiting plasma and low density lipoprotein lipid peroxidation. J. Biol. Chem 269, 16712-16719 (1994). [PubMed: 8206992]

53. Ahmed A et al. Induction of placental heme oxygenase- 1 is protective against TNFalpha-induced cytotoxicity and promotes vessel relaxation. Mol. Med 6, 391-409 (2000). [PubMed: 10952020]

54. Cudmore $\mathrm{M}$ et al. Negative regulation of soluble Flt-1 and soluble endoglin release by heme oxygenase-1. Circulation 115, 1789-1797 (2007). [PubMed: 17389265]

55. George EM et al. Induction of heme oxygenase 1 attenuates placental ischemia-induced hypertension. Hypertension 57, 941-948 (2011). [PubMed: 21383306]

56. Zhao H, Wong RJ, Kalish FS, Nayak NR \& Stevenson DK Effect of heme oxygenase-1 deficiency on placental development. Placenta 30, 861-868 (2009). [PubMed: 19699520]

57. Lian IA et al. Increased endoplasmic reticulum stress in decidual tissue from pregnancies complicated by fetal growth restriction with and without preeclampsia. Placenta 32, 823-829 (2011). [PubMed: 21907405]

58. Fu J, Zhao L, Wang L \& Zhu X Expression of markers of endoplasmic reticulum stress-induced apoptosis in the placenta of women with early and late onset severe pre-eclampsia. Taiwan. J. Obstet. Gynecol 54, 19-23 (2015). [PubMed: 25675914]

59. Kaitu'u-Lino TJ et al. Activating transcription factor 3 is reduced in preeclamptic placentas and negatively regulates sFlt-1 (soluble fms-like tyrosine kinase 1), soluble endoglin, and proinflammatory cytokines in placenta. Hypertension 70, 1014-1024 (2017). [PubMed: 28947613]

60. Ratsep MT et al. Uterine natural killer cells: supervisors of vasculature construction in early decidua basalis. Reproduction 149, R91-R102 (2015). [PubMed: 25342175]

61. Cavalli RC et al. Induced human decidual NK-like cells improve utero-placental perfusion in mice. PLOS ONE 11, e0164353 (2016). [PubMed: 27736914]

62. Hiby SE et al. Maternal activating KIRs protect against human reproductive failure mediated by fetal HLA-C2. J. Clin. Invest 120, 4102-4110 (2010). [PubMed: 20972337] This manuscript provides evidence that mismatch between maternal natural killer cell receptors and HLA-C haplotypes in the placenta may be a fundamental cause of pre-eclampsia.

63. Chazara O, Xiong S \& Moffett A Maternal KIR and fetal HLA-C: a fine balance. J. Leukoc. Biol 90, 703-716 (2011). [PubMed: 21873457]

64. Robillard PY, Dekker GA \& Hulsey TC Revisiting the epidemiological standard of preeclampsia: primigravidity or primipaternity? Eur. J. Obstet. Gynecol. Reprod. Biol 84, 37-41 (1999). [PubMed: 10413224]

65. Deen ME, Ruurda LG, Wang J \& Dekker GA Risk factors for preeclampsia in multiparous women: primipaternity versus the birth interval hypothesis. J. Matern. Fetal Neonatal Med 19, 79-84 (2006). [PubMed: 16581602]

66. Saito S \& Sakai M Th1/Th2 balance in preeclampsia. J. Reprod. Immunol 59, 161-173 (2003). [PubMed: 12896820]

67. Sasaki Y et al. Proportion of peripheral blood and decidual CD4(+) CD25(bright) regulatory T cells in pre-eclampsia. Clin. Exp. Immunol 149, 139-145 (2007). [PubMed: 17459078]

68. Girardi G Complement activation, a threat to pregnancy. Semin. Immunopathol 40, 103-111 (2018). [PubMed: 28900713]

69. Girardi G, Yarilin D, Thurman JM, Holers VM \& Salmon JE Complement activation induces dysregulation of angiogenic factors and causes fetal rejection and growth restriction. J. Exp. Med 203, 2165-2175 (2006). [PubMed: 16923853]

70. Lynch AM et al. Alternative complement pathway activation fragment $\mathrm{Bb}$ in early pregnancy as a predictor of preeclampsia. Am. J. Obstet. Gynecol 198, 385 (2008). [PubMed: 18221926]

71. Sones JL et al. Angiogenic factor imbalance precedes complement deposition in placentae of the BPH/5 model of preeclampsia. FASEB J 32, 2574-2586 (2018). [PubMed: 29279353] 
72. Vaught AJ et al. Germline mutations in the alternative pathway of complement predispose to HELLP syndrome. JCI Insight 3, 99128 (2018). [PubMed: 29563339]

73. Brocklebank V, Wood KM \& Kavanagh D Thrombotic microangiopathy and the kidney. Clin. J. Am. Soc. Nephrol 13, 300-317 (2018).

74. Hecht JL et al. The pathology of eclampsia: an autopsy series. Hypertens. Pregnancy 36, 259-268 (2017). [PubMed: 28678644]

75. Gaber LW, Spargo BH \& Lindheimer MD Renal pathology in pre-eclampsia. Baillieres Clin. Obstet. Gynaecol 8, 443-468 (1994). [PubMed: 7924017]

76. Stillman IE \& Karumanchi SA The glomerular injury of preeclampsia. J. Am. Soc. Nephrol 18, 2281-2284 (2007). [PubMed: 17634433]

77. Deen WM What determines glomerular capillary permeability? J. Clin. Invest 114, 1412-1414 (2004). [PubMed: 15545991]

78. Garovic VD et al. Urinary podocyte excretion as a marker for preeclampsia. Am. J. Obstet. Gynecol 196, 320 (2007). [PubMed: 17403404]

79. Powe CE, Levine RJ \& Karumanchi SA Preeclampsia, a disease of the maternal endothelium: the role of antiangiogenic factors and implications for later cardiovascular disease. Circulation 123, 2856-2869 (2011). [PubMed: 21690502]

80. Ahmad S \& Ahmed A Elevated placental soluble vascular endothelial growth factor receptor-1 inhibits angiogenesis in preeclampsia. Circ. Res 95, 884-891 (2004). [PubMed: 15472115]

81. Maynard SE et al. Excess placental soluble fms-like tyrosine kinase 1 (sFlt1) may contribute to endothelial dysfunction, hypertension, and proteinuria in preeclampsia. J. Clin. Invest 111, 649658 (2003). [PubMed: 12618519] This key paper demonstrates that excess sFLT1 is sufficient to induce pre-eclampsia.

82. Venkatesha $\mathrm{S}$ et al. Soluble endoglin contributes to the pathogenesis of preeclampsia. Nat. Med 12, 642-649 (2006). [PubMed: 16751767]

83. Levine RJ et al. Circulating angiogenic factors and the risk of preeclampsia. N. Engl. J. Med 350, 672-683 (2004). [PubMed: 14764923] This paper highlights the utility of angiogenic factors for use as biomarkers in the early diagnosis of pre-eclampsia.

84. Levine RJ et al. Soluble endoglin and other circulating antiangiogenic factors in preeclampsia. N. Engl. J. Med 355, 992-1005 (2006). [PubMed: 16957146]

85. Noori M, Donald AE, Angelakopoulou A, Hingorani AD \& Williams DJ Prospective study of placental angiogenic factors and maternal vascular function before and after preeclampsia and gestational hypertension. Circulation 122, 478-487 (2010). [PubMed: 20644016]

86. Park JE, Chen HH, Winer J, Houck KA \& Ferrara N Placenta growth factor. Potentiation of vascular endothelial growth factor bioactivity, in vitro and in vivo, and high affinity binding to Flt-1 but not to Flk-1/KDR. J. Biol. Chem 269, 25646-25654 (1994). [PubMed: 7929268]

87. Maynard S, Epstein FH \& Karumanchi SA Preeclampsia and angiogenic imbalance. Annu. Rev. Med 59, 61-78 (2008). [PubMed: 17937587]

88. Kendall RL \& Thomas KA Inhibition of vascular endothelial cell growth factor activity by an endogenously encoded soluble receptor. Proc. Natl Acad. Sci. USA 90, 10705-10709 (1993). [PubMed: 8248162]

89. Lu F et al. The effect of over-expression of sFlt-1 on blood pressure and the occurrence of other manifestations of preeclampsia in unrestrained conscious pregnant mice. Am. J. Obstet. Gynecol 196, 396; discussion 396 (2007). [PubMed: 17403433]

90. Li Z et al. Recombinant vascular endothelial growth factor 121 attenuates hypertension and improves kidney damage in a rat model of preeclampsia. Hypertension 50, 686-692 (2007). [PubMed: 17724276]

91. Szalai G et al. Full-length human placental sFlt-1-e15a isoform induces distinct maternal phenotypes of preeclampsia in mice. PLOS ONE 10, e0119547 (2015). [PubMed: 25860260]

92. Verlohren S, Stepan H \& Dechend R Angiogenic growth factors in the diagnosis and prediction of pre-eclampsia. Clin. Sci 122, 43-52 (2012). [PubMed: 21929511]

93. Young BC, Levine RJ \& Karumanchi SA Pathogenesis of preeclampsia. Annu. Rev. Pathol 5, 173192 (2010). [PubMed: 20078220] 
94. March MI et al. Circulating angiogenic factors and the risk of adverse outcomes among haitian women with preeclampsia. PLOS ONE 10, e0126815 (2015). [PubMed: 25965397]

95. Chaiworapongsa $\mathrm{T}$ et al. Plasma concentrations of angiogenic/anti-angiogenic factors have prognostic value in women presenting with suspected preeclampsia to the obstetrical triage area: a prospective study. J. Matern. Fetal. Neonatal Med 27, 132-144 (2014). [PubMed: 23687930]

96. Rana $\mathrm{S}$ et al. Angiogenic factors and the risk of adverse outcomes in women with suspected preeclampsia. Circulation 125, 911-919 (2012). [PubMed: 22261192]

97. Eremina V et al. VEGF inhibition and renal thrombotic microangiopathy. N. Engl. J. Med 358, 1129-1136 (2008). [PubMed: 18337603]

98. Patel TV et al. A preeclampsia-like syndrome characterized by reversible hypertension and proteinuria induced by the multitargeted kinase inhibitors sunitinib and sorafenib. J. Natl Cancer Inst 100, 282-284 (2008). [PubMed: 18270341]

99. Vigneau $\mathrm{C}$ et al. All anti-vascular endothelial growth factor drugs can induce 'pre-eclampsia-like syndrome': a RARe study. Nephrol. Dial. Transplant 29, 325-332 (2014). [PubMed: 24302609]

100. Launay-Vacher V \& Deray G Hypertension and proteinuria: a class-effect of antiangiogenic therapies. Anticancer Drugs 20, 81-82 (2009). [PubMed: 19343005]

101. Sela $\mathrm{S}$ et al. A novel human-specific soluble vascular endothelial growth factor receptor 1: celltype-specific splicing and implications to vascular endothelial growth factor homeostasis and preeclampsia. Circ. Res 102, 1566-1574 (2008). [PubMed: 18515749]

102. Tannetta DS, Dragovic RA, Gardiner C, Redman CW \& Sargent IL Characterisation of syncytiotrophoblast vesicles in normal pregnancy and pre-eclampsia: expression of Flt-1 and endoglin. PLOS ONE 8, e56754 (2013). [PubMed: 23437230]

103. Rajakumar A et al. Transcriptionally active syncytial aggregates in the maternal circulation may contribute to circulating soluble fms-like tyrosine kinase 1 in preeclampsia. Hypertension 59, 256-264 (2012). [PubMed: 22215706]

104. Redman CW et al. Review: Does size matter? Placental debris and the pathophysiology of preeclampsia. Placenta 33 (Suppl.), S48-S54 (2012). [PubMed: 22217911]

105. Vaisbuch E et al. Circulating angiogenic and antiangiogenic factors in women with eclampsia. Am. J. Obstet. Gynecol 204, 152 (2011). [PubMed: 21062661]

106. Romero R et al. A longitudinal study of angiogenic (placental growth factor) and anti-angiogenic (soluble endoglin and soluble vascular endothelial growth factor receptor-1) factors in normal pregnancy and patients destined to develop preeclampsia and deliver a small for gestational age neonate. J. Matern. Fetal Neonatal Med 21, 9-23 (2008). [PubMed: 18175241]

107. Wallace K et al. Hypertension, inflammation and $\mathrm{T}$ lymphocytes are increased in a rat model of HELLP syndrome. Hypertens. Pregnancy 33, 41-54 (2014).

108. Maharaj AS et al. VEGF and TGF-beta are required for the maintenance of the choroid plexus and ependyma. J. Exp. Med 205, 491-501 (2008). [PubMed: 18268040]

109. Saleh L, Verdonk K, Visser W, van den Meiracker AH \& Danser AH The emerging role of endothelin-1 in the pathogenesis of pre-eclampsia. Ther. Adv. Cardiovasc. Dis 10, 282-293 (2016). [PubMed: 26755746]

110. Verdonk K, Visser W, Van Den Meiracker AH \& Danser AH The renin-angiotensin-aldosterone system in pre-eclampsia: the delicate balance between good and bad. Clin. Sci 126, 537-544 (2014). [PubMed: 24400721]

111. Burke SD et al. Soluble fms-like tyrosine kinase 1 promotes angiotensin II sensitivity in preeclampsia. J. Clin. Invest 126, 2561-2574 (2016). [PubMed: 27270170]

112. Wallukat $\mathrm{G}$ et al. Patients with preeclampsia develop agonistic autoantibodies against the angiotensin AT1 receptor. J. Clin. Invest 103, 945-952 (1999). [PubMed: 10194466] This paper is the first to demonstrate a biological role for autoantibodies against the angiotensin AT1 receptor.

113. Zhou CC et al. Angiotensin receptor agonistic autoantibodies induce pre-eclampsia in pregnant mice. Nat. Med 14, 855-862 (2008). [PubMed: 18660815]

114. Hubel CA et al. Agonistic angiotensin II type 1 receptor autoantibodies in postpartum women with a history of preeclampsia. Hypertension 49, 612-617 (2007). [PubMed: 17210828] 
115. Xia Y \& Kellems RE Angiotensin receptor agonistic autoantibodies and hypertension: preeclampsia and beyond. Circ. Res 113, 78-87 (2013). [PubMed: 23788505]

116. Quitterer U et al. Beta-arrestin1 prevents preeclampsia by downregulation of mechanosensitive AT1-B2 receptor heteromers. Cell 176, 318-333 (2018). [PubMed: 30503206]

117. Osol G et al. Placental growth factor is a potent vasodilator of rat and human resistance arteries. Am. J. Physiol. Heart Circ. Physiol 294, H1381-H1387 (2008). [PubMed: 18192215]

118. Zhang HH, Chen JC, Sheibani L, Lechuga TJ \& Chen DB Pregnancy augments VEGF-stimulated in vitro angiogenesis and vasodilator (NO and $\mathrm{H} 2 \mathrm{~S}$ ) production in human uterine artery endothelial cells. J. Clin. Endocrinol. Metab 102, 2382-2393 (2017). [PubMed: 28398541]

119. Pimentel AM et al. L-Arginine-nitric oxide pathway and oxidative stress in plasma and platelets of patients with pre-eclampsia. Hypertens. Res 36, 783-788 (2013). [PubMed: 23575380]

120. Sandrim VC et al. Nitric oxide formation is inversely related to serum levels of antiangiogenic factors soluble fms-like tyrosine kinase- 1 and soluble endogline in preeclampsia. Hypertension 52, 402-407 (2008). [PubMed: 18574068]

121. Zeng Y, Li M, Chen Y \& Wang S Homocysteine, endothelin-1 and nitric oxide in patients with hypertensive disorders complicating pregnancy. Int. J. Clin. Exp. Pathol 8, 15275-15279 (2015). [PubMed: 26823880]

122. Goncalves-Rizzi VH, Possomato-Vieira JS, Sales Graca TU, Nascimento RA \& Dias-Junior CA Sodium nitrite attenuates hypertension-in-pregnancy and blunts increases in soluble fms-like tyrosine kinase-1 and in vascular endothelial growth factor. Nitric Oxide 57, 71-78 (2016). [PubMed: 27181106]

123. Osol G, Ko NL \& Mandala M Altered endothelial nitric oxide signaling as a paradigm for maternal vascular maladaptation in preeclampsia. Curr. Hypertens. Rep 19, 82 (2017). [PubMed: 28942512]

124. Lankhorst S, Danser AH \& van den Meiracker AH Endothelin-1 and antiangiogenesis. Am. J. Physiol. Regul. Integr. Comp. Physiol 310, R230-R234 (2016). [PubMed: 26511523]

125. George EM \& Granger JP Endothelin: key mediator of hypertension in preeclampsia. Am. J. Hypertens 24, 964-969 (2011). [PubMed: 21677700]

126. Kingman M, Ruggiero R \& Torres F Ambrisentan, an endothelin receptor type A-selective endothelin receptor antagonist, for the treatment of pulmonary arterial hypertension. Expert Opin. Pharmacother 10, 1847-1858 (2009). [PubMed: 19601701]

127. Wang K et al. Dysregulation of hydrogen sulfide producing enzyme cystathionine gamma-lyase contributes to maternal hypertension and placental abnormalities in preeclampsia. Circulation 127, 2514-2522 (2013). [PubMed: 23704251]

128. Holwerda KM et al. Hydrogen sulfide attenuates sFlt1-induced hypertension and renal damage by upregulating vascular endothelial growth factor. J. Am. Soc. Nephrol 25, 717-725 (2014). [PubMed: 24335973]

129. Snijder PM et al. Sodium thiosulfate attenuates angiotensin II-induced hypertension, proteinuria and renal damage. Nitric Oxide 42, 87-98 (2014). [PubMed: 25459997]

130. Gant NF, Daley GL, Chand S, Whalley PJ \& MacDonald PC A study of angiotensin II pressor response throughout primigravid pregnancy. J. Clin. Invest 52, 2682-2689 (1973). [PubMed: 4355997]

131. Saxena AR et al. Increased sensitivity to angiotensin II is present postpartum in women with a history of hypertensive pregnancy. Hypertension 55, 1239-1245 (2010). [PubMed: 20308605]

132. Germain AM et al. Endothelial dysfunction: a link among preeclampsia, recurrent pregnancy loss, and future cardiovascular events? Hypertension 49, 90-95 (2007). [PubMed: 17116761]

133. Gammill HS, Lin C \& Hubel CA Endothelial progenitor cells and preeclampsia. Front. Biosci 12, 2383-2394 (2007). [PubMed: 17127248]

134. O'Brien TE, Ray JG \& Chan WS Maternal body mass index and the risk of preeclampsia: a systematic overview. Epidemiology 14, 368-374 (2003). [PubMed: 12859040]

135. Catalano PM, Tyzbir ED, Roman NM, Amini SB \& Sims EA Longitudinal changes in insulin release and insulin resistance in nonobese pregnant women. Am. J. Obstet. Gynecol 165, 16671672 (1991). [PubMed: 1750458] 
136. Chisholm KM \& Folkins AK Placental and clinical characteristics of term small-for-gestationalage neonates: a case-control study. Pediatr. Dev. Pathol 19, 37-46 (2016). [PubMed: 26368794]

137. Fuh MM et al. Resistance to insulin-mediated glucose uptake and hyperinsulinemia in women who had preeclampsia during pregnancy. Am. J. Hypertens 8, 768-771 (1995). [PubMed: 7546505]

138. Martinez Abundis E, Gonzalez Ortiz M, Quinones Galvan A \& Ferrannini E Hyperinsulinemia in glucose-tolerant women with preeclampsia. A controlled study. Am. J. Hypertens 9, 610-614 (1996). [PubMed: 8783787]

139. Arkwright PD, Rademacher TW, Dwek RA \& Redman CW Pre-eclampsia is associated with an increase in trophoblast glycogen content and glycogen synthase activity, similar to that found in hydatidiform moles. J. Clin. Invest 91, 2744-2753 (1993). [PubMed: 8514882]

140. Scioscia $\mathrm{M}$ et al. Insulin resistance in human preeclamptic placenta is mediated by serine phosphorylation of insulin receptor substrate-1 and -2. J. Clin. Endocrinol. Metab 91, 709-717 (2006). [PubMed: 16332940]

141. Thadhani $\mathrm{R}$ et al. Insulin resistance and alterations in angiogenesis: additive insults that may lead to preeclampsia. Hypertension 43, 988-992 (2004). [PubMed: 15023932]

142. Sandgren JA et al. Arginine vasopressin infusion is sufficient to model clinical features of preeclampsia in mice. JCI Insight 3, e99403 (2018).

143. Rana S, Karumanchi SA \& Lindheimer MD Angiogenic factors in diagnosis, management, and research in preeclampsia. Hypertension 63, 198-202 (2014). [PubMed: 24166749]

144. Baltajian K et al. Sequential plasma angiogenic factors levels in women with suspected preeclampsia. Am. J. Obstet. Gynecol 215, 89.e1-89.e10 (2016). [PubMed: 26827880]

145. Rana S et al. Angiogenic biomarkers in triage and risk for preeclampsia with severe features. Pregnancy Hypertens 13, 100-106 (2018). [PubMed: 30177034]

146. Rana $\mathrm{S}$ et al. Clinical characterization and outcomes of preeclampsia with normal angiogenic profile. Hypertens. Pregnancy 32, 189-201 (2013). [PubMed: 23725084]

147. Kleinrouweler CE et al. Accuracy of circulating placental growth factor, vascular endothelial growth factor, soluble fms-like tyrosine kinase 1 and soluble endoglin in the prediction of preeclampsia: a systematic review and meta-analysis. BJOG 119, 778-787 (2012). [PubMed: 22433027]

148. Kusanovic JP et al. A prospective cohort study of the value of maternal plasma concentrations of angiogenic and anti-angiogenic factors in early pregnancy and midtrimester in the identification of patients destined to develop preeclampsia. J. Matern. Fetal. Neonatal Med 22, 1021-1038 (2009). [PubMed: 19900040]

149. Moore Simas TA et al. Angiogenic biomarkers for prediction of early preeclampsia onset in highrisk women. J. Matern. Fetal. Neonatal Med 27, 1038-1048 (2014). [PubMed: 24066977]

150. Chappell LC et al. Diagnostic accuracy of placental growth factor in women with suspected preeclampsia: a prospective multicenter study. Circulation 128, 2121-2131 (2013). [PubMed: 24190934]

151. Erez $\mathrm{O}$ et al. The change in concentrations of angiogenic and anti-angiogenic factors in maternal plasma between the first and second trimesters in risk assessment for the subsequent development of preeclampsia and small-for-gestational age. J. Matern. Fetal. Neonatal Med 21, 279-287 (2008). [PubMed: 18446652]

152. Chaiworapongsa $\mathrm{T}$ et al. Maternal plasma concentrations of angiogenic/antiangiogenic factors in the third trimester of pregnancy to identify the patient at risk for stillbirth at or near term and severe late preeclampsia. Am. J. Obstet. Gynecol 208, 287.e1-287.e15 (2013). [PubMed: 23333542]

153. Chaiworapongsa $\mathrm{T}$ et al. Evidence supporting a role for blockade of the vascular endothelial growth factor system in the pathophysiology of preeclampsia. Young Investigator Award. Am. J. Obstet. Gynecol 190, 1541-1547; discussion 1547-1550 (2004). [PubMed: 15284729]

154. Leanos-Miranda A et al. Changes in circulating concentrations of soluble fms-like tyrosine kinase-1 and placental growth factor measured by automated electrochemiluminescence immunoassays methods are predictors of preeclampsia. J. Hypertens 30, 2173-2181 (2012). [PubMed: 22902831] 
155. Chaiworapongsa $T$ et al. Plasma soluble vascular endothelial growth factor receptor-1 concentration is elevated prior to the clinical diagnosis of preeclampsia. J. Matern. Fetal. Neonatal Med 17, 3-18 (2005). [PubMed: 15804781]

156. Moore AG et al. Angiogenic biomarkers for prediction of maternal and neonatal complications in suspected preeclampsia. J. Matern. Fetal. Neonatal Med 25, 2651-2657 (2012). [PubMed: 22861812]

157. Zeisler $\mathrm{H}$ et al. Predictive value of the sFlt-1:PlGF ratio in women with suspected preeclampsia. N. Engl. J. Med 374, 13-22 (2016). [PubMed: 26735990] This large prospective clinical study demonstrates a utility for serum angiogenic biomarkers in women with suspected pre-eclampsia.

158. Zeisler H et al. The sFlt-1/PIGF Ratio: ruling out preeclampsia for up to 4 weeks and the value of retesting. Ultrasound Obstet. Gynecol 10.1002/uog.19178 (2018).

159. Schnettler WT et al. Cost and resource implications with serum angiogenic factor estimation in the triage of pre-eclampsia. BJOG 120, 1224-1232 (2013). [PubMed: 23647884]

160. Hadker $\mathrm{N}$ et al. Financial impact of a novel preeclampsia diagnostic test versus standard practice: a decision-analytic modeling analysis from a UK healthcare payer perspective. J. Med. Econ 13, 728-737 (2010). [PubMed: 21138338]

161. Rolfo A et al. Chronic kidney disease may be differentially diagnosed from preeclampsia by serum biomarkers. Kidney Int 83, 177-181 (2013). [PubMed: 23014459]

162. Verdonk K et al. Differential diagnosis of preeclampsia: remember the soluble fms-like tyrosine kinase 1/placental growth factor ratio. Hypertension 60, 884-890 (2012). [PubMed: 22892815]

163. Verlohren $\mathrm{S}$ et al. The sFlt-1/PIGF ratio in different types of hypertensive pregnancy disorders and its prognostic potential in preeclamptic patients. Am. J. Obstet. Gynecol 206, 58 (2012). [PubMed: 22000672]

164. Young B et al. The use of angiogenic biomarkers to differentiate non-HELLP related thrombocytopenia from HELLP syndrome. J. Matern. Fetal. Neonatal Med 23, 366-370 (2010). [PubMed: 19701867]

165. Perni $U$ et al. Angiogenic factors in superimposed preeclampsia: a longitudinal study of women with chronic hypertension during pregnancy. Hypertension 59, 740-746 (2012). [PubMed: 22311907]

166. Leanos-Miranda A et al. Circulating angiogenic factors and the risk of preeclampsia in systemic lupus erythematosus pregnancies. J. Rheumatol 42, 1141-1149 (2015). [PubMed: 25979720]

167. Kim MY et al. Angiogenic factor imbalance early in pregnancy predicts adverse outcomes in patients with lupus and antiphospholipid antibodies: results of the PROMISSE study. Am. J. Obstet. Gynecol 214, 108.e1-108.e14 (2016). [PubMed: 26432463]

168. Chaiworapongsa $\mathrm{T}$ et al. The use of angiogenic biomarkers in maternal blood to identify which SGA fetuses will require a preterm delivery and mothers who will develop pre-eclampsia. J. Matern. Fetal. Neonatal Med 29, 1214-1228 (2016). [PubMed: 26303962]

169. Buyon JP et al. Predictors of pregnancy outcomes in patients with lupus: a cohort study. Ann. Intern. Med 163, 153-163 (2015). [PubMed: 26098843]

170. Hagmann H, Thadhani R, Benzing T, Karumanchi SA \& Stepan H The promise of angiogenic markers for the early diagnosis and prediction of preeclampsia. Clin. Chem 58, 837-845 (2012). [PubMed: 22431894]

171. Sovio $U$ et al. Prediction of preeclampsia using the soluble fms-like tyrosine kinase 1 to placental growth factor ratio: a prospective cohort study of unselected nulliparous women. Hypertension 69, 731-738 (2017). [PubMed: 28167687]

172. Poon LC, Kametas NA, Maiz N, Akolekar R \& Nicolaides KH First-trimester prediction of hypertensive disorders in pregnancy. Hypertension 53, 812-818 (2009). [PubMed: 19273739]

173. Rolnik DL et al. Aspirin versus placebo in pregnancies at high risk for preterm preeclampsia. N. Engl. J. Med 377, 613-622 (2017). [PubMed: 28657417] This prospective clinical trial demonstrates that aspirin, when given to high-risk women early in pregnancy, can prevent preterm pre-eclampsia.

174. Charkiewicz K, Jasinska E \& Laudanski P Identification of proteomic biomarkers of preeclampsia using protein microarray and tandem mass spectrometry [Polish]. Postepy Hig. Med. Dosw 69, 562-570 (2015). 
175. Law KP, Han TL, Tong C \& Baker PN Mass spectrometry-based proteomics for pre-eclampsia and preterm birth. Int. J. Mol. Sci 16, 10952-10985 (2015). [PubMed: 26006232]

176. Kenny LC et al. Robust early pregnancy prediction of later preeclampsia using metabolomic biomarkers. Hypertension 56, 741-749 (2010). [PubMed: 20837882]

177. Spaans F, de Vos P, Bakker WW, van Goor H \& Faas MM Danger signals from ATP and adenosine in pregnancy and preeclampsia. Hypertension 63, 1154-1160 (2014). [PubMed: 24688119]

178. Bahado-Singh RO et al. First-trimester metabolomic detection of late-onset preeclampsia. Am. J. Obstet. Gynecol 208, 58 (2013). [PubMed: 23159745]

179. Kuc S et al. Metabolomics profiling for identification of novel potential markers in early prediction of preeclampsia. PLOS ONE 9, e98540 (2014). [PubMed: 24873829]

180. Hahn S, Rusterholz C, Hosli I \& Lapaire O Cell-free nucleic acids as potential markers for preeclampsia. Placenta 32 (Suppl.), S17-S20 (2011). [PubMed: 21257079]

181. Purwosunu $Y$ et al. Prediction of preeclampsia by analysis of cell-free messenger RNA in maternal plasma. Am. J. Obstet. Gynecol 200, 386 (2009). [PubMed: 19217595]

182. Sekizawa A et al. Prediction of pre-eclampsia by an analysis of placenta-derived cellular mRNA in the blood of pregnant women at 15-20 weeks of gestation. BJOG 117, 557-564 (2010). [PubMed: 20121832]

183. Farina A et al. Performance of messenger RNAs circulating in maternal blood in the prediction of preeclampsia at 10-14 weeks. Am. J. Obstet. Gynecol 203, 575 (2010). [PubMed: 20934680]

184. Bergmann A et al. Reduction of circulating soluble Flt-1 alleviates preeclampsia-like symptoms in a mouse model. J. Cell. Mol. Med 14, 1857-1867 (2010). [PubMed: 19538465]

185. Gilbert JS et al. Recombinant vascular endothelial growth factor 121 infusion lowers blood pressure and improves renal function in rats with placentalischemia-induced hypertension. Hypertension 55, 380-385 (2010). [PubMed: 20026764]

186. Siddiqui AH et al. Recombinant vascular endothelial growth factor 121 attenuates autoantibodyinduced features of pre-eclampsia in pregnant mice. Am. J. Hypertens 24, 606-612 (2011). [PubMed: 21183928]

187. Makris A et al. Placental growth factor reduces blood pressure in a uteroplacental ischemia model of preeclampsia in nonhuman primates. Hypertension 67, 1263-1272 (2016). [PubMed: 27091894]

188. Spradley FT et al. Placental growth factor administration abolishes placental ischemia-induced hypertension. Hypertension 67, 740-747 (2016). [PubMed: 26831193]

189. Santiago-Font JA et al. Serelaxin improves the pathophysiology of placental ischemia in the reduced uterine perfusion pressure rat model of preeclampsia. Am. J. Physiol. Regul. Integr. Comp. Physiol 311, R1158-R1163 (2016). [PubMed: 27629886]

190. Ashar-Patel A et al. FLT1 and transcriptome-wide polyadenylation site (PAS) analysis in preeclampsia. Sci. Rep 7, 12139 (2017). [PubMed: 28939845]

191. Turanov AA et al. RNAi modulation of placental sFLT1 for the treatment of preeclampsia. Nat. Biotechnol 36, 1164-1173 (2018).

192. Paauw ND et al. Sildenafil during pregnancy: a preclinical meta-analysis on fetal growth and maternal blood pressure. Hypertension 70, 998-1006 (2017). [PubMed: 28893896]

193. Mandala M \& Osol G Physiological remodelling of the maternal uterine circulation during pregnancy. Bas. Clin. Pharmacol. Toxicol 110, 12-18 (2012).

194. Trapani A Jr. et al. Perinatal and hemodynamic evaluation of sildenafil citrate for preeclampsia treatment: a randomized controlled trial. Obstet. Gynecol 128, 253-259 (2016). [PubMed: 27400005]

195. Pels A et al. STRIDER (Sildenafil TheRapy in dismal prognosis early onset fetal growth restriction): an international consortium of randomised placebo-controlled trials. BMC Pregnancy Childbirth 17, 440 (2017). [PubMed: 29282009]

196. Hawkes N Trial of Viagra for fetal growth restriction is halted after baby deaths. BMJ 362, k3247 (2018). [PubMed: 30045911] 
197. Rana S et al. Ouabain inhibits placental sFlt1 production by repressing HSP27-dependent HIF-1alpha pathway. FASEB J 28, 4324-4334 (2014). [PubMed: 24970393]

198. Kalafat E, Sukur YE, Abdi A, Thilaganathan B \& Khalil A Metformin for the prevention of hypertensive disorders of pregnancy in women with gestational diabetes and obesity: a systematic review and meta-analysis. Ultrasound Obstet. Gynecol 52, 706-714 (2018). [PubMed: 29749110]

199. Brownfoot FC et al. Metformin as a prevention and treatment for preeclampsia: effects on soluble fms-like tyrosine kinase 1 and soluble endoglin secretion and endothelial dysfunction. Am. J. Obstet. Gynecol 214, 356.e1-356.e15 (2016). [PubMed: 26721779]

200. Cluver CA et al. Esomeprazole to treat women with preterm preeclampsia: a randomised placebo controlled trial. Am. J. Obstet. Gynecol 219, 388.e1-388.e17 (2018). [PubMed: 30055127]

201. Kaitu'u-Lino TJ et al. Combining metformin and esomeprazole is additive in reducing sFlt-1 secretion and decreasing endothelial dysfunction - implications for treating preeclampsia. PLOS ONE 13, e0188845 (2018). [PubMed: 29466360]

202. Klingel R, Gohlen B, Schwarting A, Himmelsbach F \& Straube R Differential indication of lipoprotein apheresis during pregnancy. Ther. Apher. Dial 7, 359-364 (2003). [PubMed: 12924613]

203. Thadhani R et al. Pilot study of extracorporeal removal of soluble fms-like tyrosine kinase 1 in preeclampsia. Circulation 124, 940-950 (2011). [PubMed: 21810665] This proof-of-concept clinical study demonstrates that removal of sFLT1 was associated with improvement of preeclamptic signs and extension of pregnancy.

204. Thadhani $\mathrm{R}$ et al. Removal of soluble fms-like tyrosine kinase-1 by dextran sulfate apheresis in preeclampsia. J. Am. Soc. Nephrol 27, 903-913 (2016). [PubMed: 26405111]

205. Roberts JM et al. Vitamins C and E to prevent complications of pregnancy-associated hypertension. N. Engl. J. Med 362, 1282-1291 (2010). [PubMed: 20375405]

206. Haddad B et al. Enoxaparin and aspirin compared with aspirin alone to prevent placenta-mediated pregnancy complications: a randomized controlled trial. Obstet. Gynecol 128, 1053-1063 (2016). [PubMed: 27741174]

207. Roberge S, Bujold E \& Nicolaides KH Aspirin for the prevention of preterm and term preeclampsia: systematic review and metaanalysis. Am. J. Obstet. Gynecol 218, 287-293 (2018). [PubMed: 29138036]

208. LeFevre ML \& U.S. Preventive Services Task Force. Low-dose aspirin use for the prevention of morbidity and mortality from preeclampsia: U.S. Preventive Services Task Force recommendation statement. Ann. Intern. Med 161, 819-826 (2014). [PubMed: 25200125]

209. Poston L et al. Vitamin C and vitamin E in pregnant women at risk for pre-eclampsia (VIP trial): randomised placebo-controlled trial. Lancet 367, 1145-1154 (2006). [PubMed: 16616557]

210. Covarrubias AE et al. AP39, a modulator of mitochondrial bioenergetics, reduces anti-angiogenic response and oxidative stress in hypoxia-exposed trophoblasts: relevance for preeclampsia pathogenesis. Am. J. Pathol 189, 104-114 (2018). [PubMed: 30315766]

211. Vaka VR et al. Role of mitochondrial dysfunction and reactive oxygen species in mediating hypertension in the reduced uterine perfusion pressure rat model of preeclampsia. Hypertension 72, 703-711 (2018). [PubMed: 30012871]

212. Girardi G Pravastatin to treat and prevent preeclampsia. Preclinical and clinical studies. J. Reprod. Immunol 124, 15-20 (2017). [PubMed: 29028516]

213. Ramma W \& Ahmed A Therapeutic potential of statins and the induction of heme oxygenase- 1 in preeclampsia. J. Reprod. Immunol 101-102, 153-160 (2014).

214. Costantine MM et al. Using pravastatin to improve the vascular reactivity in a mouse model of soluble fms-like tyrosine kinase-1-induced preeclampsia. Obstet. Gynecol 116, 114-120 (2010). [PubMed: 20567176]

215. Kumasawa K et al. Pravastatin induces placental growth factor (PGF) and ameliorates preeclampsia in a mouse model. Proc. Natl Acad. Sci. USA 108, 1451-1455 (2011). [PubMed: 21187414]

216. Saad AF et al. Pravastatin effects on placental prosurvival molecular pathways in a mouse model of preeclampsia. Reprod. Sci 23, 1593-1599 (2016). [PubMed: 27170663] 
217. Saad AF et al. Effects of pravastatin on angiogenic and placental hypoxic imbalance in a mouse model of preeclampsia. Reprod. Sci 21, 138-145 (2014). [PubMed: 23749761]

218. Brownfoot FC et al. Effects of simvastatin, rosuvastatin and pravastatin on soluble fms-like tyrosine kinase 1 (sFlt-1) and soluble endoglin (sENG) secretion from human umbilical vein endothelial cells, primary trophoblast cells and placenta. BMC Pregnancy Childbirth 16, 117 (2016). [PubMed: 27207105]

219. Chaiworapongsa $\mathrm{T}$ et al. Pravastatin for the prevention of adverse pregnancy outcome: preeclampsia and more? J. Matern. Fetal Neonatal Med 30, 3 (2017). [PubMed: 27161513]

220. Brownfoot FC et al. Effects of pravastatin on human placenta, endothelium, and women with severe preeclampsia. Hypertension 66, 687-697; discussion 445 (2015). [PubMed: 26222708]

221. Lefkou E et al. Pravastatin improves pregnancy outcomes in obstetric antiphospholipid syndrome refractory to antithrombotic therapy. J. Clin. Invest 126, 2933-2940 (2016). [PubMed: 27454295]

222. Costantine MM et al. Safety and pharmacokinetics of pravastatin used for the prevention of preeclampsia in high-risk pregnant women: a pilot randomized controlled trial. Am. J. Obstet. Gynecol 214, 720.e1-720.e17 (2016). [PubMed: 26723196]

223. Chen CW, Jaffe IZ \& Karumanchi SA Pre-eclampsia and cardiovascular disease. Cardiovasc. Res 101, 579-586 (2014). [PubMed: 24532051]

224. Ahmed R, Dunford J, Mehran R, Robson S \& Kunadian V Pre-eclampsia and future cardiovascular risk among women: a review. J. Am. Coll. Cardiol 63, 1815-1822 (2014). [PubMed: 24613324]

225. Mosca L et al. Effectiveness-based guidelines for the prevention of cardiovascular disease in women - 2011 update: a guideline from the American Heart Association. J. Am. Coll. Cardiol 57, 1404-1423 (2011). [PubMed: 21388771]

226. Bellamy L, Casas JP, Hingorani AD \& Williams DJ Pre-eclampsia and risk of cardiovascular disease and cancer in later life: systematic review and meta-analysis. BMJ 335, 974 (2007). [PubMed: 17975258] This paper provides a systematic review on the relationship between preeclampsia and long-term CVD.

227. Leslie MS \& Briggs LA Preeclampsia and the risk of future vascular disease and mortality: a review. J. Midwifery Womens Health 61, 315-324 (2016). [PubMed: 27155218]

228. Veerbeek JH et al. Cardiovascular disease risk factors after early-onset preeclampsia, late-onset preeclampsia, and pregnancy-induced hypertension. Hypertension 65, 600-606 (2015). [PubMed: 25561694]

229. Al-Nasiry S et al. Metabolic syndrome after pregnancies complicated by pre-eclampsia or smallfor-gestational-age: a retrospective cohort. BJOG 122, 1818-1823 (2015). [PubMed: 25318833]

230. Bello N, Rendon ISH \& Arany Z The relationship between pre-eclampsia and peripartum cardiomyopathy: a systematic review and meta-analysis. J. Am. Coll. Cardiol 62, 1715-1723 (2013). [PubMed: 24013055]

231. Patten IS et al. Cardiac angiogenic imbalance leads to peripartum cardiomyopathy. Nature 485 , 333-338 (2012). [PubMed: 22596155]

232. Shahul $\mathrm{S}$ et al. Circulating antiangiogenic factors and myocardial dysfunction in hypertensive disorders of pregnancy. Hypertension 67, 1273-1280 (2016). [PubMed: 27113052]

233. Vikse BE, Irgens LM, Leivestad T, Skjaerven R \& Iversen BM Preeclampsia and the risk of endstage renal disease. N. Engl. J. Med 359, 800-809 (2008). [PubMed: 18716297] This paper is the first to link pre-eclampsia with future ESRD.

234. McDonald SD, Han Z, Walsh MW, Gerstein HC \& Devereaux PJ Kidney disease after preeclampsia: a systematic review and meta-analysis. Am. J. Kidney Dis 55, 1026-1039 (2010). [PubMed: 20346562]

235. Tangren JS et al. Pregnancy outcomes after clinical recovery from AKI. J. Am. Soc. Nephrol 28, 1566-1574 (2017). [PubMed: 28008002] This paper reports that a prior history of acute kidney injury is a major risk factor for pre-eclampsia.

236. Piccoli GB et al. Risk of adverse pregnancy outcomes in women with CKD. J. Am. Soc. Nephrol 26, 2011-2022 (2015). [PubMed: 25766536]

237. Pruthi D et al. Exposure to experimental preeclampsia in mice enhances the vascular response to future injury. Hypertension 65, 863-870 (2015). [PubMed: 25712723] 
238. Bytautiene $\mathrm{E}$ et al. Long-term alterations in maternal plasma proteome after sFlt1-induced preeclampsia in mice. Am. J. Obstet. Gynecol 208, 388.e1-388.e10 (2013). [PubMed: 23497796]

239. Wang A et al. Circulating anti-angiogenic factors during hypertensive pregnancy and increased risk of respiratory distress syndrome in preterm neonates. J. Matern. Fetal Neonatal Med 25, 1447-1452 (2012). [PubMed: 22097923]

240. Hansen AR, Barnes CM, Folkman J \& McElrath TF Maternal preeclampsia predicts the development of bronchopulmonary dysplasia. J. Pediatr 156, 532-536 (2010). [PubMed: 20004912]

241. Thebaud B \& Abman SH Bronchopulmonary dysplasia: where have all the vessels gone? Roles of angiogenic growth factors in chronic lung disease. Am. J. Respir. Crit. Care Med 175, 978-985 (2007). [PubMed: 17272782]

242. Vuorela $P$ et al. Amniotic fluid—soluble vascular endothelial growth factor receptor-1 in preeclampsia. Obstet. Gynecol 95, 353-357 (2000). [PubMed: 10711543]

243. Tang JR, Karumanchi SA, Seedorf G, Markham N \& Abman SH Excess soluble vascular endothelial growth factor receptor-1 in amniotic fluid impairs lung growth in rats: linking preeclampsia with bronchopulmonary dysplasia. Am. J. Physiol. Lung Cell. Mol. Physiol 302, L36-L46 (2012). [PubMed: 22003089]

244. Yu XD, Branch DW, Karumanchi SA \& Zhang J Preeclampsia and retinopathy of prematurity in preterm births. Pediatrics 130, e101-e107 (2012). [PubMed: 22665405]

245. Sibai BM et al. Risk factors associated with preeclampsia in healthy nulliparous women. The Calcium for Preeclampsia Prevention (CPEP) Study Group. Am. J. Obstet. Gynecol 177, 10031010 (1997). [PubMed: 9396883] 


\section{Key points}

- $\quad$ Pre-eclampsia is defined as new-onset hypertension and proteinuria or other end-organ damage such as to the liver or brain occurring after 20 weeks of pregnancy.

- Pre-eclampsia is characterized by defective placentation, placental ischaemia, abnormal spiral artery remodelling, oxidative stress at the maternal-fetal interface and angiogenic imbalance in the maternal circulation with ensuing endothelial and end-organ damage.

- High levels of antiangiogenic factors and low levels of proangiogenic factors are useful biomarkers for the early detection and prognosis of pre-eclampsia; these markers also serve astheranostics in clinical trials.

- Delivery is currently the only definitive treatment for pre-eclampsia; aspirin is recommended for prevention of pre-eclampsia in women at high risk.

- Potential therapeutic strategies for pre-eclampsia include targeted apheresis, antibody therapies, RNA interference and small-molecule inhibitors of factors that have a role in placental dysfunction.

- $\quad$ Evidence is emerging of long-term increased risk of cardiovascular and kidney disease in women who have experienced pre-eclampsia; pre-eclampsia is also an important risk factor for neonatal respiratory distress syndrome and bronchopulmonary dysplasia. 


\section{Box 11}

\section{Risk factors for pre-eclampsia 21,245}

\section{Positive risk factors}

- $\quad$ Family history of pre-eclampsia

- $\quad$ Nulliparity

- $\quad$ Multiple pregnancy

- $\quad$ Advanced maternal age

- In vitro fertilization

- Maternal comorbidities, including diabetes mellitus, chronic hypertension, obesity, chronic kidney disease, history of acute kidney injury or systemic lupus erythematosus

- Previous placental abruption or intrauterine fetal growth restriction

- $\quad$ Trisomy 13

- Molar pregnancies

\section{Negative risk factors}

- $\quad$ Maternal smoking

- Prolonged sexual cohabitation 


\section{Hydatidiform mole}

A gestational, trophoblastic disease that occurs after aberrant fertilization, originates in the placenta and has potential to invade the uterus and metastasize.

\section{Trisomy 13}

A severe chromosomal disorder caused by an extra copy of chromosome 13 that is characterized by multiple congenital abnormalities with a classic triad of abnormally small or missing eyes, cleft lip and/or palate and extra digits.

\section{Genome-wide association study}

An analysis of markers (usually single-nucleotide polymorphisms] across the entire genome to identify those that are statistically more or less common in one population (often patients with a specific disease) than in another population (typically people who are unaffected by the specific disease). 


\section{Spiral arteries}

Small arteries derived from uterine arteries that supply blood to the endometrium of the uterus during the luteal phase of the menstrual cycle. These arteries are remodelled into highly dilated vessels by the action of invading trophoblasts during normal pregnancy to support the growing demands of the fetus.

\section{Foam cells}

Cells that contain vacuoles or fat-laden macrophages seen in atherosclerosis. 


\section{HELLP syndrome}

A complication of pregnancy that is characterized by a syndrome of haemolysis, elevated liver enzymes and low platelet count. 


\section{Haemosiderin}

An insoluble form of tissue storage iron. 


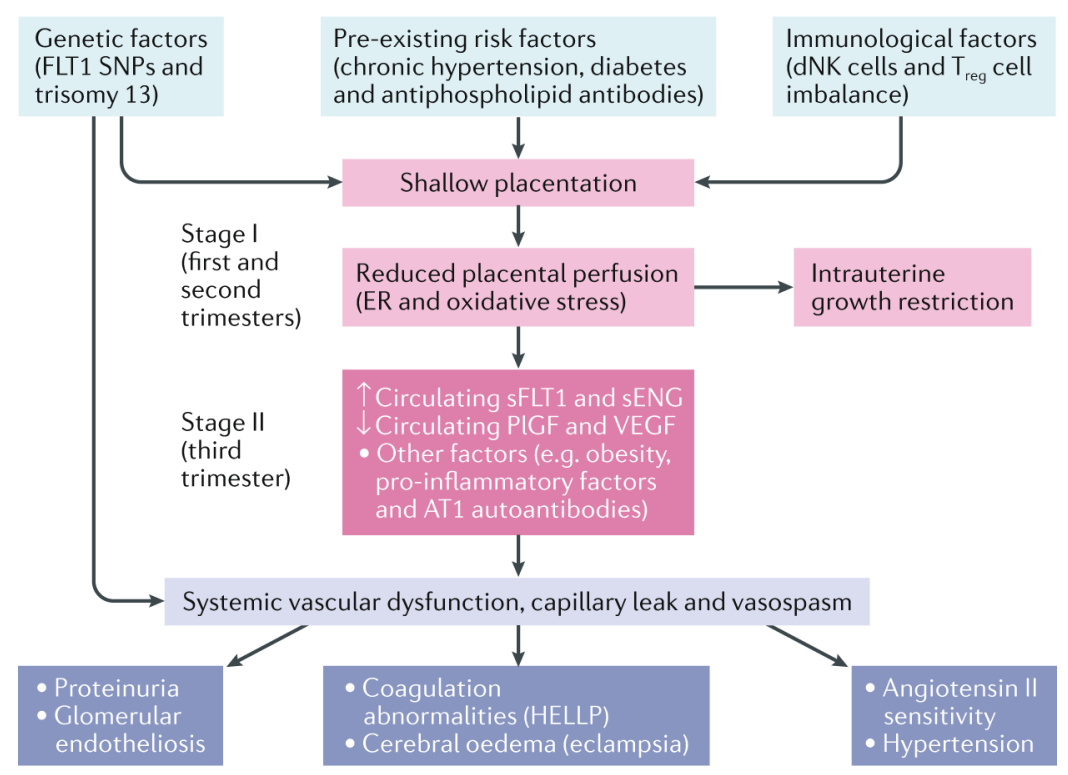

Fig. 1 I. The pathogenesis of pre-eclampsia.

Genetic factors, maternal factors and immunological factors may cause placental dysfunction (stage I), which in turn leads to the release of antiangiogenic factors (such as soluble fms-like tyrosine kinase 1 (sFLT1) and soluble endoglin (sENG)) and other inflammatory mediators that induce preeclampsia (stage II). AT1, angiotensin II type I receptor; dNK, decidual natural killer; ER, endoplasmic reticulum; HELLP, haemolysis, elevated liver enzymes and low platelet count; PIGF, placental growth factor; SNP, singlenucleotide polymorphism; $\mathrm{T}_{\mathrm{reg}}$, regulatory $\mathrm{T}$ cell; VEGF, vascular endothelial growth factor. 


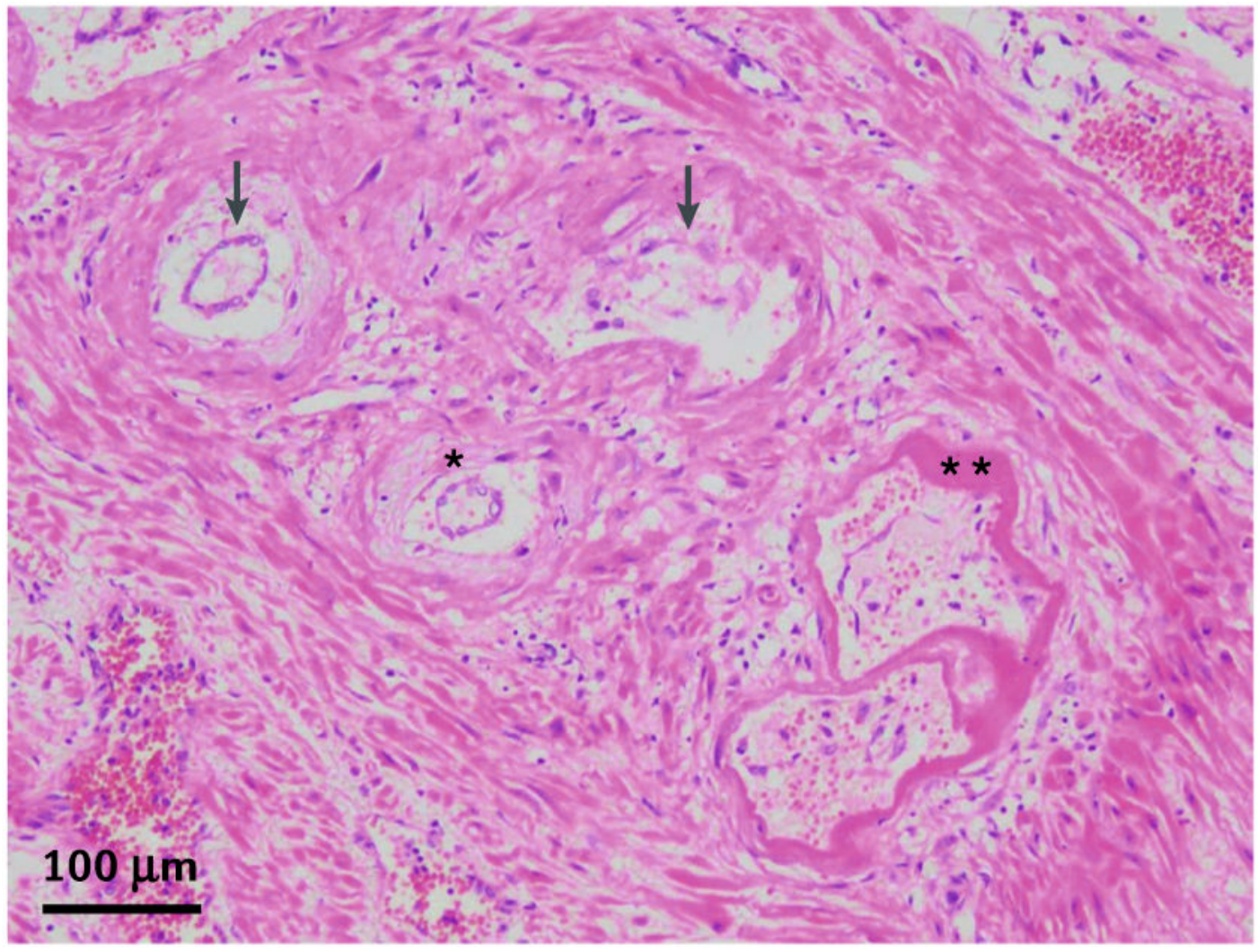

Fig. 2 I. Decidual vasculopathy in a pre-eclamptic placenta.

Image showing a sample of the placental bed of the uterus from a patient with decidual vasculopathy in the third trimester that is stained with haematoxylin and eosin. The vessels show chronic injury with endothelial fragmentation and detachment (arrow) as well as fibrinoid necrosis $(* *)$ and remodelling (*) of the vessel wall. Adapted from REF. ${ }^{74}$. The pathology of eclampsia: an autopsy series, Hecht, J. L. et al., Hypertension in Pregnancy, 2017, by permission of the publisher (Taylor \& Francis Ltd, http://www.tandfonline.com). 


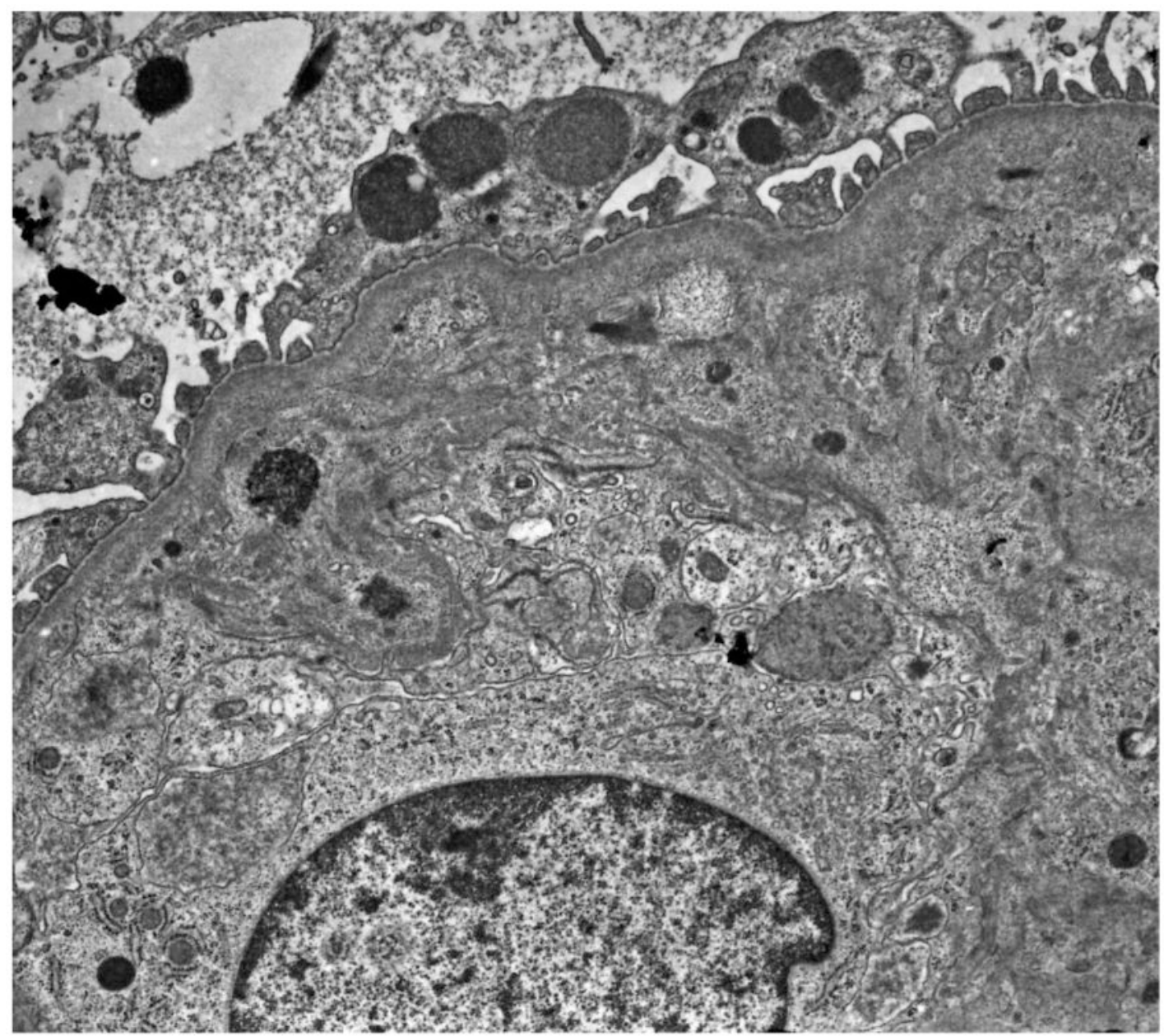

Fig. 3 I. Glomerular endotheliosis.

Electron micrograph showing glomerular endotheliosis with occlusion of the capillary lumen by swollen endothelial cells in a pregnant women with new-onset hypertension and proteinuria ( $3.7 \mathrm{~g}$ per day). Podocytes show protein resorption granules with preservation of their foot processes. Original magnification $\times 8,000$. Image courtesy of I. Stillman, Beth Israel Deaconess Medical Center, USA. 
a

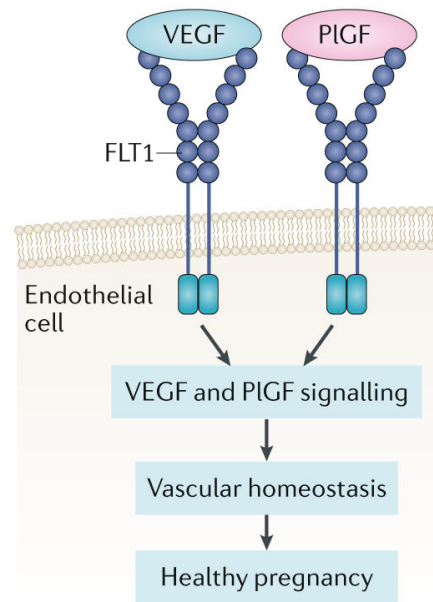

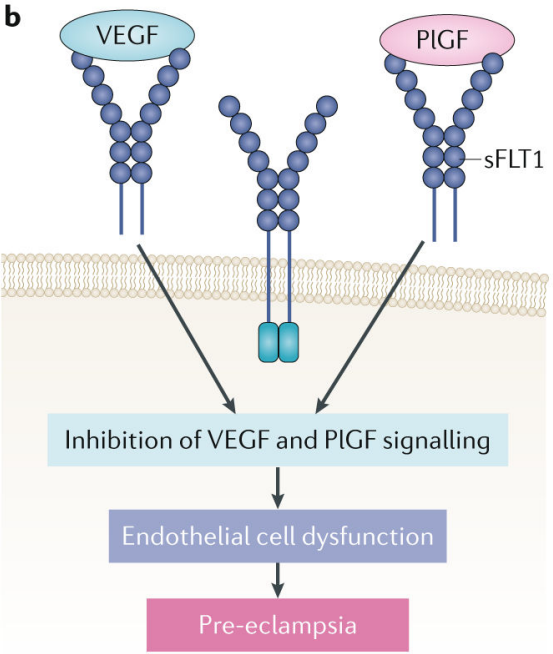

Fig. 4 I. The role of sFLT1 in endothelial dysfunction in pre-eclampsia.

a I During normal pregnancy, vascular homeostasis is maintained by physiological levels of vascular endothelial growth factor (VEGF) and placental growth factor (PIGF) signalling in the vasculature by binding to its receptor fms-like tyrosine kinase 1 (FLT1) and other signalling receptors. b I In pre-eclampsia, excess soluble FLT1 (sFLT1) is secreted by the placenta and binds local and circulating VEGF and PlGF, resulting in inhibition of VEGF and PIGF signalling in the vasculature. This inhibition results in endothelial cell dysfunction, including reduced production of prostacyclin and nitric oxide and the release of procoagulant proteins. 


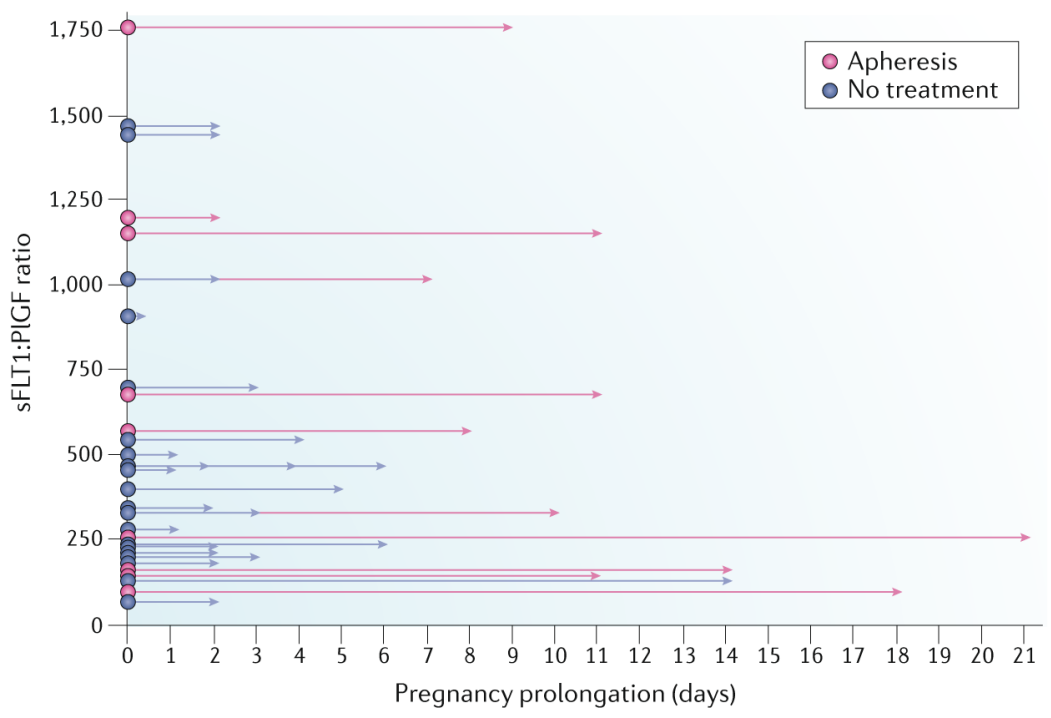

Fig. 5 I. Dextran-sulfate apheresis enables prolongation of pregnancy in women with preeclampsia.

Pretreatment soluble fms-like tyrosine kinase 1 (sFLT1):placental growth factor (PlGF) ratios and pregnancy prolongation in women with pre-eclampsia who were treated with apheresis and untreated contemporaneous controls. Pregnancy continued for 8 days (range $2-11)$ and 15 days (range 11-21) in women treated once $(n=6)$ and multiple times $(n=5)$, respectively, compared with 3 days (range 0-14) in untreated contemporaneous women with pre-eclampsia $(n=22)$. Republished with permission of American Society of Nephrology, from Thadani et al., Removal of soluble fms-like tyrosine kinase 1 by dextran sulfate apheresis in preeclampsia. Journal of the American Society of Nephrology 27 (2016) (REF. 204 ). 